\title{
La guerra medieval a través de su registro arqueológico: el asedio al castillo santiaguista de Montizón (1465-1467) ${ }^{1}$
}

\section{The medieval war through its archaeological record: the siege of the castle of the Order of Santiago de Montizón (1465- 1467)}

\author{
David Gallego Valle \\ Universidad de Castilla-La Mancha \\ David.gallegovalle@uclm.es \\ https://orcid.org/0000-0002-8215-8308
}

Fecha de recepción: 27-05-2020

Fecha de aceptación: 11-12-2020

\section{RESUMEN}

En este trabajo queremos reconstruir el asedio que se dio en el castillo de Montizón (Villamanrique, Ciudad Real) entre 1465 y 1467, usando una metodología que combina los estudios arqueológicos y el análisis de las fuentes documentales. En este sentido, este texto se enmarca en una corriente de investigación aún novedosa en España como es la denominada "arqueología del combate", vertiente de los estudios sobre la materialidad de la guerra que está mucho más consolidada dentro de los ámbitos académicos anglosajones. Los hechos que aquí se analizan se encuadran en la guerra que se produjo entre el infante Alfonso de Ávila y su tío Enrique IV a raíz de la "Farsa de Ávila" de 1465, donde el monarca es depuesto a favor de su sobrino por una facción muy importante de la nobleza de Castilla, en la que entró en juego, además, el control de la orden de Santiago entre diversos linajes nobiliarios. Entre estas luchas por el poder destacó, por su virulencia, el campo de operaciones que se dio a ambos lados de Sierra Morena y que enfrentó a los Manrique, entre otros, con los Lucas de Iranzo, siendo la pugna por la encomienda y castillo de Montizón uno de los puntos clave de estos hechos.

Palabras clave: Arqueología del Conflicto, Orden de Santiago, Lucas de Iranzo, linaje Manrique, Enrique IV

Topónimos: Castillo de Montizón

Periodo: Siglo XV

1 Esta publicación se enmarca en el proyecto de investigación Órdenes militares y religiosidad en el Occidente medieval y el Oriente latino (siglos XII-1/2 XVI). Ideología, memoria y cultura material, PGC2018096531-B-I00, financiado por el Ministerio de Ciencia, Innovación y Universidades (MCIU), la Agencia Estatal de Investigación (AEI) y el Fondo Europeo de Desarrollo Regional (FEDER). 


\section{ABSTRACT}

This work seeks to reconstruct the siege of the castle of Montizón (Villamanrique, Ciudad Real) between 1465 and 1467, using a methodology that combines archaeological studies and the analysis of documentary sources. In this sense, this text is part of a research trend that is still new in Spain, the so-called "archaeology of combat", a branch of studies on the materiality of warfare that is far more established within Anglo-Saxon academic circles. The events analysed here are part of the war between Prince Alfonso of Ávila and his uncle Henry IV following the "Farce of Ávila" of 1465, when the monarch was deposed in favour of his nephew by a very important faction of the nobility of Castile, in which the contest for control of the Order of Santiago between different noble lineages also came into play. Amongst these struggles for power, the field of operations on both sides of the Sierra Morena stands out for its virulence. The latter pitted the Manriques, amongst others, against the Lucas of Iranzo, the struggle for the encomienda and castle of Montizón being one of the key points of these events. Henry IV

Key words: archaeology of conflict, Order of Santiago, Lucas de Iranzo, lineage Manrique,

Toponyms: Montizón Castle.

Period: 15th century.

\section{INTRODUCCIÓN}

En la primavera de 1465, un contingente armado bajo las órdenes de Pedro de Manrique, hijo de Rodrigo Manrique, puso cerco al castillo de Montizón (Villamanrique, Ciudad Real). Los acontecimientos, bien narrados en los Hechos del Condestable don Miguel Lucas de Iranzo, se desarrollaron hasta 1467 con la capitulación de la fortaleza que, a partir de ese momento, pasó a formar parte junto con el resto de la encomienda del extenso señorío de los Manrique, situándose a su cabeza la figura del ilustre poeta Jorge Manrique. Este hecho de armas, como veremos a continuación, no ha sido tratado hasta el momento en un estudio monográfico y las referencias que tenemos sobre el mismo se han enfocado, por los diversos autores que lo mencionan, desde la información que aportan las fuentes documentales.

Analizando la producción bibliográfica en la que se cita este hecho de armas encontramos las alusiones que realiza Mercado (1995b: 94-100) al estudiar los comendadores de Montizón y Chiclana, donde se basa, entre otros, en los datos contenidos en la Hechos del Condestable y en la Historia de la Genealogía de la Casa de Lara realizada por Salazar y Castro. Menciones puntuales al asedio hacen también Cooper (1991: 64), Pretel (2011) así como Madrid (1988), esta última al tratar la encomienda de Montizón y la figura de Jorge Manrique. De gran interés es la visión de Martín (2010: 68-69) en la que, al analizar de una forma crítica el texto de los Hechos del Condestable, aporta una perspectiva novedosa sobre algunas de las decisiones militares que se dieron en el cerco y que el autor de la Crónica pudo tergiversar por motivos laudatorios. Más recientemente, en estudios centrados en el Campo de Montiel, se analiza brevemente este episodio en el trabajo de Fernández-Pacheco y Moya (2015), aunque la referencia más extensa la encontramos en Rubio (2017: 83-86) al hacer una síntesis sobre esta comarca en la Edad Media. Por otro lado, dentro de nuestro trabajo de tesis (Gallego, 2020), hemos podido estudiar tanto el castillo de Montizón como el resto de las fortificaciones del entorno, lo que nos ha permitido documentar, mediante diversas herramientas arqueológicas, tanto el asedio como las operaciones satélites del mismo. 
Teniendo en cuenta la inexistencia de un estudio del cerco desde una perspectiva material, en este texto hemos aplicado las líneas de trabajo que se vienen desarrollando en la denominada "arqueología del conflicto", rama de investigación de esta disciplina que en tierras norteamericanas y del norte de Europea se ha aplicado en los estudios de varios lugares para el periodo medieval como pueden ser, por citar algunos, los desarrollados para la batallas de Crecy (Livingston y Devries, 2015) o Angicourt (Curry, 2005) o el interesante proyecto arqueológico en el castillo de Kolno en Polonia (Lech, 2014). Una dinámica similar encontramos en Portugal, donde se han centrado los esfuerzos en la investigación y la recuperación del campo de batalla de Aljubarrota ${ }^{2}$, así como la investigación de algunos cercos de época medieval por Gomes (2016). En España, este tipo de investigaciones se han aplicado, hasta no hace mucho tiempo, en el marco de la Guerra Civil Española (Schnell y Baltuille, 2017: 169-202). No obstante, con el avance de las nuevas tecnologías se están realizando importantes proyectos como el que desarrolla la Universidad de Jaén para el estudio de la batalla de Baecula (Bellón et al., 2004), donde a través de la prospección geomagnética y el uso de S.I.G. han podido reconstruir este hecho de armas documentando el movimiento de las tropas, en un caso muy similar al desarrollado, aunque aún en un estadio primitivo, para la batalla de Cutanda que analiza el choque entre aragoneses y almorávides en 1118.

En tierras manchegas contamos con tres lugares excepcionales para el estudio de la guerra medieval desde la perspectiva de su materialidad. El primero es Alarcos, donde se dio la batalla homónima en 1195 y en el que se pudo recuperar una fosa de despojos excepcional de este encuentro armando (V.V.A.A., 1995). Relacionada con el mismo, muy próxima, se localiza la antigua ciudad musulmana de Calatrava La Vieja donde, durante las excavaciones, se han registrado evidencias muy significativas, especialmente de armamento y utillaje, del asedio que sufrió el lugar por las tropas cruzadas en la campaña de Las Navas de 1212 (Retuerce y Hervás, 2002). Finalmente, el proyecto más reciente y aún en pleno desarrollo es la investigación para el conocimiento de la batalla y asedio de Montiel $^{3}$ que se dio en esta localidad en el año 1369 entre las tropas del rey Pedro I y Enrique de Trastámara. En estos trabajos se están realizando prospecciones geomagnéticas y tradicionales que han permitido, hasta el momento, localizar parte de los escenarios de las escaramuzas y de la batalla que se narran en las crónicas, así como del cerco que se dio posteriormente cuyos elementos materiales se han registrado en las excavaciones del castillo.

Siguiendo esta línea de trabajo, en las páginas siguientes analizaremos el asedio de Montizón partiendo de las fuentes escritas, tanto de los Hechos del Condestable como de los Libros de Visita de la Orden de Santiago, pero nuestra principal aportación vendrá de los datos arqueológicos que tenemos relacionados con este hecho de armas que, hasta el momento, son totalmente inéditos. En este sentido, en primer lugar, realizaremos un contexto geohistórico para poder encuadrar el asedio en su tiempo y espacio, ya que, al fin y al cabo, las luchas por el control de la encomienda de Montizón fueron una más de las consecuencias de las disputas nobiliarias por la preeminencia de ciertos linajes en el seno de la orden de Santiago. Seguidamente llevaremos a cabo el estudio propiamente dicho del cerco y de las operaciones militares paralelas, en el que haremos un análisis combinado

2 Los trabajos en el campo de batalla de Aljubarrota, en los que hemos podido participar como investigadores secundarios, están dirigidos por María Antonia Castro Amaral dentro de un Projecto de Investigação Plurianual de Arqueología que realiza el Ministerio de Cultura de Portugal y la Fundaçao Batalha de Aljubarrota.

3 Estos trabajos comenzaron en 2018 y se enmarcan en el "Proyecto de Investigación Arqueología de la batalla de Montiel: Excavación, prospección y estudio poliorcético. Montiel (Ciudad Real), dirigido por J. Molero de la Universidad de Castilla-La Mancha, financiados por la Junta de Comunidades de Castilla-La Mancha, en los que colabora el Ayuntamiento de Montiel y la Fundación Castillo de La Estrella de Montiel. 
de las fuentes escritas con los diversos estudios arqueológicos para lo que se aportará, además, un cuerpo cartográfico con los resultados

\section{CONTEXTO GEOHISTÓRICO DEL ASEDIO DE MONTIZÓN}

La disputa por la encomienda de Montizón, que se centralizó en el asedio de su fortaleza homónima, se enmarcó en la guerra civil que enfrentó al príncipe Alfonso, proclamado rey por una gran parte de la nobleza castellana, y el monarca Enrique IV entre los años de 1465 y 1468. En este sentido, aunque los primeros tiempos de este reinado se habían desarrollado con una cierta "tranquilidad", siendo aceptado el monarca por la mayor parte de los señores (Sánchez, 2001: 76-77) y enfocándose las actividades bélicas hacia los conflictos exteriores en los reinos de Navarra y Aragón, incluso reactivándose la guerra contra Granada, cuya acción más relevante fue la toma de Huéscar en 1458 (Echevarria, 2004:147-148), a partir de 1464 se aprecia una nueva escalada de tensión interna (Monsalve, 2017). Aunque las causas y los hechos de ésta son de una profundidad y extensión que no podemos tratar aquí, sí que queremos incidir, por lo menos, en el análisis de los bandos nobiliarios y sus motivaciones -en los que las órdenes militares estuvieron muy presentes (García y Novoa, 2018: 385) - , que se enfrentaron tras producirse la declaración del Manifiesto de Burgos de 1464, preludio de la "Farsa de Ávila" de 1465, en la que Enrique IV fue depuesto y se proclamó rey a su sobrino, el infante Alfonso (Martín, 2003: 151-152).

A la cabeza del bando alfonsino (Val, 1991: 48), en el que se agrupaba gran parte de la nobleza más tradicional del reino, se puso el marqués de Villena, Juan Pacheco, que en los años previos al inicio del conflicto había visto cómo su poder iba mermando en favor los nuevos linajes que iba encumbrando Enrique IV. Acompañaban al marqués su hermano, Pedro Girón, maestre de Calatrava, y el arzobispo Carrillo a los que se sumaron otra serie de nobles como fueron los Manrique. Frente a ellos, en el bando del monarca, se encontraba gran parte de la nueva nobleza, así como importantes ciudades del reino, entre la que destacaban dos personajes que habían ido ascendiendo rápidamente desde baja cuna como eran Beltrán de las Cueva (Carceller, 2006: 788-789), conde de Ledesma, y el condestable de Castilla, Lucas de Iranzo, así como otras casas que fueron cambiando su adhesión en función del desarrollo de los acontecimientos.

En esta guerra se litigaba, además, por el control de las órdenes militares, instituciones que en ese momento acaparaban un inmenso patrimonio en el reino. Este hecho venía a mostrar una realidad latente desde fines del siglo XIII y que se fue acentuando a lo largo del siglo XV como fue la patrimonialización de estas milicias y las disputas por sus posesiones (Ayala Martínez, 1997). En este sentido, como bien estudió Rodriguez Llopis (1996) para la orden de Santiago, a lo largo de la Baja Edad Media son varios linajes los que medran en esta milicia para acumular las principales encomiendas y, a través de ellas, poder acceder a los cargos más relevantes. Dentro de estas facciones nobiliarias, que se entremezclan entre sí a través de alianzas forjadas por matrimonios, se encuentran, entre otras, la de los Suarez de Figueroa, Cárdenas, Ayala y Álvarez de Toledo, la propia de los Manrique $\mathrm{y}$, a partir del segundo cuarto del siglo XV, fueron haciendo su aparición los Pacheco que tendrán un papel fundamental a partir de mediados de la centuria, $y$, en menor medida, los Iranzo que tendrán su continuación con los Cámara.

Bien es verdad que el caso más paradigmático para este momento histórico, el patrimonio que acumulaba esta institución, fue la disputa en el seno de la orden de Santiago, cuyo maestrazgo había quedado vacante tras la muerte de Álvaro de Luna en 1453. En este contexto, como ha estudiado Ayala (1997: 276-282), la cabeza de la Orden estuvo sin representación durante los primeros años del reinado de Enrique IV que, al igual que su padre Juan II, consiguió una bula papal para regir la institución y poder nombrar directamente a los maestres. Fruto de esta situación, las encomiendas y 
bienes santiaguistas sufrieron tiempos de transformación pero también de destrucción ${ }^{4}$, como hemos podido documentar en diversos estudios arqueológicos (Molero y Gallego, 2020) y en las descripciones recogidas en las visitaciones. Por otro lado, las injerencias del monarca provocaron la pérdida de poder dentro de la institución de los antiguos linajes, en especial de los Manrique, a favor de personajes más cercanos al rey, lo que causó un hondo malestar en estos sectores (Pretel, 2011: 262).

En este clima de fricción, el punto de inflexión, que tendrá gran trascendencia en los hechos de armas a lo que dedicamos este trabajo, fue la disputa por ocupar el cargo de la encomienda de Montizón en 1458 (Martín, 2003: 138-139). La misma estaba ubicada en el corazón de los dominios de los Manrique que, desde la posición de Segura de la Sierra de la que era comendador Rodrigo Manrique, habían acumulado un amplio señorío tanto en la vertiente jiennense de Sierra Morena como en las tierras al sur de la Mancha, en especial en el Campo de Montiel. Hasta este momento, la administración de Montizón había estado ocupada por un personaje próximo a este linaje, como era Garcilaso de la Vega, cuñado de Rodrigo, pero su inesperada muerte en una algarada en la vega de Granada ${ }^{5}$ supuso que el cargo quedara vacante. Los Manrique pidieron a Enrique IV que se designara al hijo del fallecido como nuevo comendador de Montizón, con el fin de mantener en su poder la encomienda, pero el monarca, contraviniendo este deseo que respaldaba gran parte de la nobleza, nombró para el mismo a Diego Lucas de Iranzo ${ }^{6}$, hermano del condestable de Castilla, lo que puso el caldo de cultivo para el enfrentamiento que se produciría siete años después.

La incorporación de la encomienda de Montizón a las posesiones de los Iranzo suponía una merma para el patrimonio de los Manrique, a la vez que proporcionaba al bando del Condestable una posición preeminente al norte de Sierra Morena frente a sus enemigos. Además, este hecho dio un nuevo empujón al ascenso de los Iranzo, linaje que ascendió principalmente por el patronazgo regio y no por acciones militares (Etxeberria, 2019: 651) al que sumaron, rápidamente, la encomienda de Oreja, lo que les permitió ir medrando en el seno de la Orden. Por otro lado, Enrique IV comenzó los movimientos para designar, tras varios años vacante, el maestrazgo de Santiago. Este, finalmente, recayó en 1464 en su privado Beltrán de La Cueva (Carceller, 2006: 788), aunque a punto estuvo de hacerlo en Miguel Lucas de Iranzo, lo que hubiera supuesto una grave violación del testamento de Juan II que había dejado reservada esta dignidad para el infante Alfonso ${ }^{7}$. Ante las presiones de la nobleza, el privado renunció al maestrazgo (Ayala, 1997: 280), algo que no parece que fuera efectivo en la realidad, por lo que, tras desatarse la guerra civil, Enrique siguió teniendo el control efectivo de parte de esta institución gracias a las posesiones de la nobleza afín al mismo.

Dentro de este contexto de confusión, que dará paso a una guerra abierta en junio de 1465 (Arias, 2018: 95), los Manrique desde sus enclaves en la Sierra del Segura y el Campo de Montiel, comenzaron a atacar las posiciones de ciudades y plazas leales a Enrique IV. Fruto de estas acciones se produjo el asedio de Alcaraz (Albacete), estudiado en detalle por Pretel (1978: 128-130), en el que Pedro Manrique junto con sus hermanos, Jorge y Diego, cercaron la ciudad que resistió de forma tenaz. Por otro lado, parte de sus efectivos se dedicaron a atacar enclaves de la orden de Santiago en manos de sus rivales que culminaron, en este mismo año, con la toma de Yeste que se encontraba en manos

\footnotetext{
4 Primera Historia de la Orden de Santiago, (ed. 1978, p. 390)

5 Historia Genealógica de la Casa de Lara..., (ed. 1697, p. 295)

6 Crónica de Enrique IV, (ed. 1904, p. 284)

7 Crónica de las tres Órdenes..., (ed. 1572, p. 64)
} 
de un familiar de Beltrán de La Cueva (Pretel, 2011: 309). Finalmente, Pedro Manrique junto con el maestre de Calatrava, Pedro Girón, iniciaron dos operaciones de expugnación en el señorío de los Lucas de Iranzo, atacando de forma paralela ambas vertientes de Sierra Morena. Mientras que el calatravo ponía cerco a la ciudad de Jaén (Rodríguez, 2012: 121-122), Pedro, junto con una importante hueste, comenzó el sitio del castillo de Montizón del que se había partido apresurado su comendador, Diego Lucas de Iranzo, muy probablemente ante el temor de quedar copado en esta plaza.

\section{EL ASEDIO DE MONTIZÓN (1465-1467)}

El asedio a la fortaleza de Montizón fue, como en la mayor parte de los cercos medievales, un hecho de armas de cierta complejidad y que no solo afectó al propio castillo, sino a todo el territorio circundante, a ambos lados de Sierra Morena. Con el fin de poder estudiar la operación en todas sus dimensiones, hemos dividido los hechos en tres apartados que responden, a grandes rasgos, a las fases de ésta. En el primero, analizaremos la fisonomía de la fortaleza de Montizón y su espacio de influencia en este momento histórico, intentando comprender, además, desde un análisis poliorcético, cómo debió ser el desarrollo de la disposición del bloqueo de la plaza y las actividades de expugnación que llevaron a construir a los Manrique un castillo padrastro en las cercanías, algo que se documenta en otras operaciones militares medievales (Palacios, 2006) así como en acciones bélicas coetáneas en el tiempo como la que tuvo lugar en la pugna por el castillo extremeño de Montánchez (Rodríguez, 2017: 37). En el segundo, estudiaremos el desarrollo de la cabalgada en el marco del primer socorro a la fortaleza y que culminó con el asalto y la destrucción del castillo padrastro en el cercano cerro de la Horca. En el tercero, analizaremos los acontecimientos que se desarrollaron desde 1466 hasta la capitulación del castillo en 1467 y que, en este caso, se trató de una guerra de posiciones y desgaste, con cabalgadas constantes, que no ha dejado evidencias materiales sustanciosas en el entorno de la fortaleza pero sí que nos permiten reconstruir el paisaje, la caminería y el poblamiento de su espacio circundante.

\subsection{El castillo de Montizón y los intentos de expugnación (febrero-noviembre 1465)}

La encomienda de Montizón, con la fortaleza homónima a su cabeza, se extendía en el siglo XV a ambos lados de Sierra Morena, contando con posesiones tanto en el Campo de Montiel como en el Alto Guadalquivir, entre las actuales provincias de Ciudad Real y Jaén, como bien ha estudiado Porras (1997: 257-258). Entre las mismas existían villas como de las de Torre de Juan Abad y, especialmente, Chiclana que contaban con más de mil vecinos y cuantiosas rentas (Mercado, 1995a). Por otro lado se localizaban varias aldeas, como el caso de Belmontejo de la Sierra que, en 1474, obtuvo el villazgo por parte de Rodrigo Manrique. Por otro lado, en las proximidades, se erigían varias fortalezas, aunque algunas de ellas estaban ya en proceso de abandono como era la torre de la Higuera, situada a 3 $\mathrm{km}$ al norte, o el propio recinto de Chiclana que, para esas fechas, aún poseía una potencia defensiva de envergadura ${ }^{8}$.

Bien es verdad que los emolumentos y prebendas más importantes de la encomienda estaban relacionados tanto con las numerosas vías y cañadas que atravesaban la misma, de las que se cobraban los pasos correspondientes mediante portazgos y montazgos ${ }^{9}$,

8 Año de 1227. Tumbo Menor de Castilla (ed. 2016: Lib. 1, 218-220, doc. 29). Desde el año 1227 la orden de Santiago tenía establecido el montazgo en Santiago que, en un primer momento, se correspondía con el castillo de Eznavexor y, desde la segunda mitad del siglo XIII, paso a la fortaleza de Santiago de Montizón.

9 Año de 1478. Archivo Histórico Nacional (AHN), Órdenes Militares (OO.MM), Libro 1063, Visita a los 
como por la presencia de monopolios como eran, por ejemplo, la extracción de leña para carbón en sus terrenos. Por sus tierras, en las que se extendían varias dehesas, algunas de ellas muy próximas al castillo, cruzaba la cañada que, procedente, por el norte, de Torre de Juan Abad y controlada por el torreón de la Higuera, cruzaba Sierra Morena por los pasos hacia Santiesteban del Puerto y Torre Alver.

Figura 1. Localización del castillo de Montizón

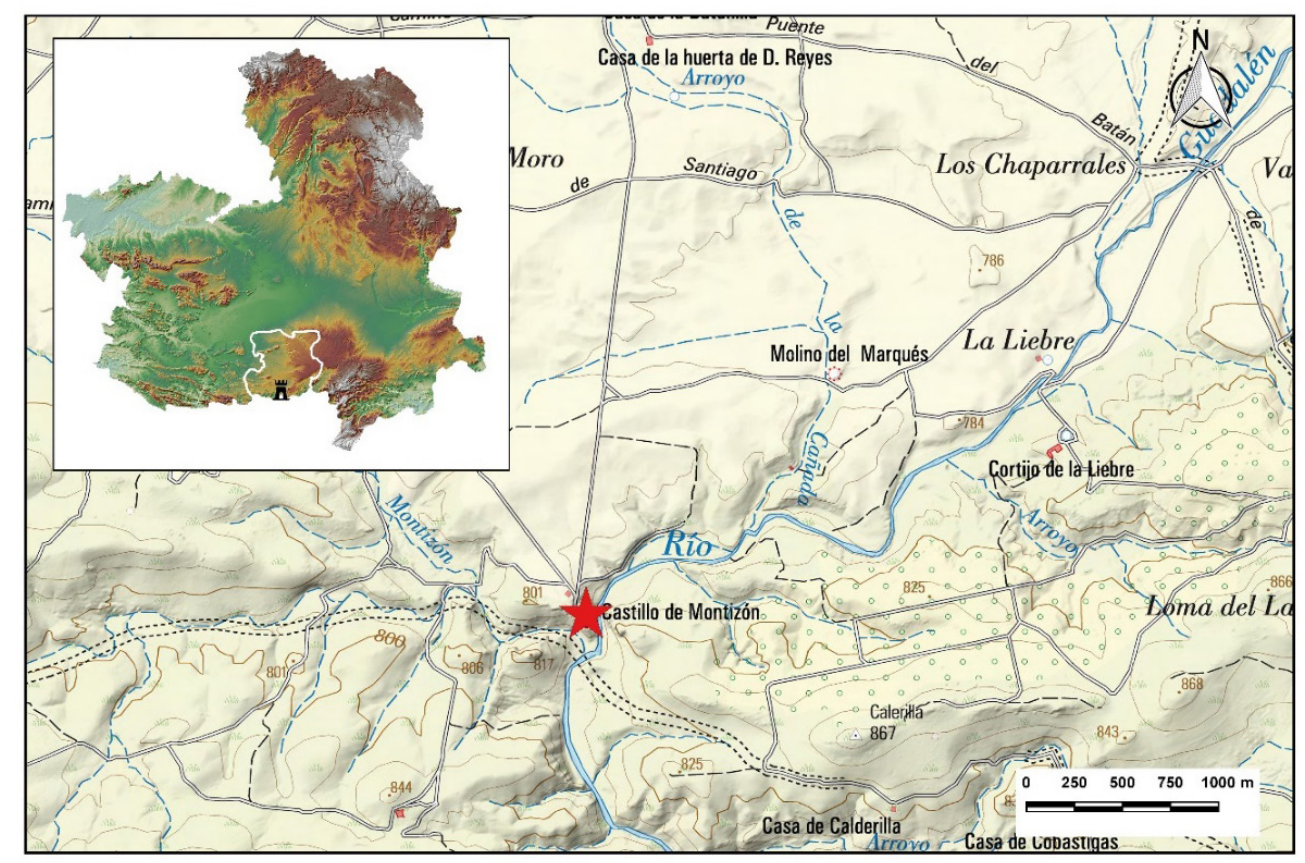

Fuente: Elaboración propia ${ }^{10}$

Como hemos mencionado, a la cabeza de esta encomienda, ocupando un punto estratégico clave, se localizaba el castillo de Montizón. El mismo, como ya hemos estudiado en trabajos previos (Gallego, 2016; Gallego, 2020), se edificó entre fines del siglo XIII e inicios del XIV, sustituyendo a la antigua fortaleza islámica de Eznavexor y heredando la denominación de Santiago. La fisonomía de este recinto militar, sobre el que no nos podemos detener en detalle, responde a lo que el profesor Molero ha denominado castilloscasas de la encomienda (2005: 657-670), aunque en este caso presenta un carácter muy militarizado con la presencia de importantes novedades poliorcéticas.

El edificio fue fundado sobre una gran peña cuarcítica cortada tanto por el río Guadalén como el arroyo de Montizón, lo que proporcionaba unas defensas naturales muy marcadas tanto al sur como al oeste. Se componía de tres recintos que se iban cerrando sobre sí mismos y un albacar en el costado occidental. Este último, en el que se abría la denominada puerta del Río, estaba dedicado a las actividades agropecuarias y tenía un amplio espacio para la guarda de ganado. Rodeando el cuerpo principal de la fortaleza, salvo la Torre del Homenaje, se situaba un antemuro, denominado el albaiçin en las visitaciones ${ }^{11}$, que se 
iba adaptando a la topografía del terreno. Este antemuro o recinto exterior contaba con dos puertas, la que comunicaba con el albacar y, en el costado oriental, un portillo citado como de La Higuera que permitía la aguada y la salida hacia las huertas. En el costado norte, el más accesible, existía un potente foso excavado en la roca, hoy en día parcialmente colmatado, en el que se abría un portillo que ha dado lugar al acceso actual.

El cuerpo de la fortaleza propiamente dicho estaba articulado en torno a un patio central, en el que existían todo un conjunto de estancias de servicio y almacenaje así como una serie de aljibes para la recogida del agua de lluvia, uno de ellos de gran potencia y que se conserva prácticamente intacto en la actualidad. Este espacio tenía dos puertas, la de Hierro, que era el acceso principal a la fortaleza, ubicada en el frente oeste y, en el lado contrario, se abría un portillo que permitía acceder a liza del antemuro. Finalmente, en el frente meridional se situaba la Torre del Homenaje, separada por una barrera del resto del patio, con dos plantas distribuidas en torno a un pequeño patio en el que existía un aljibe, coronándose con una terraza defensiva.

Figura 2. Vista general (desde el noreste) del castillo de Montizón en la antesala de Sierra Morena

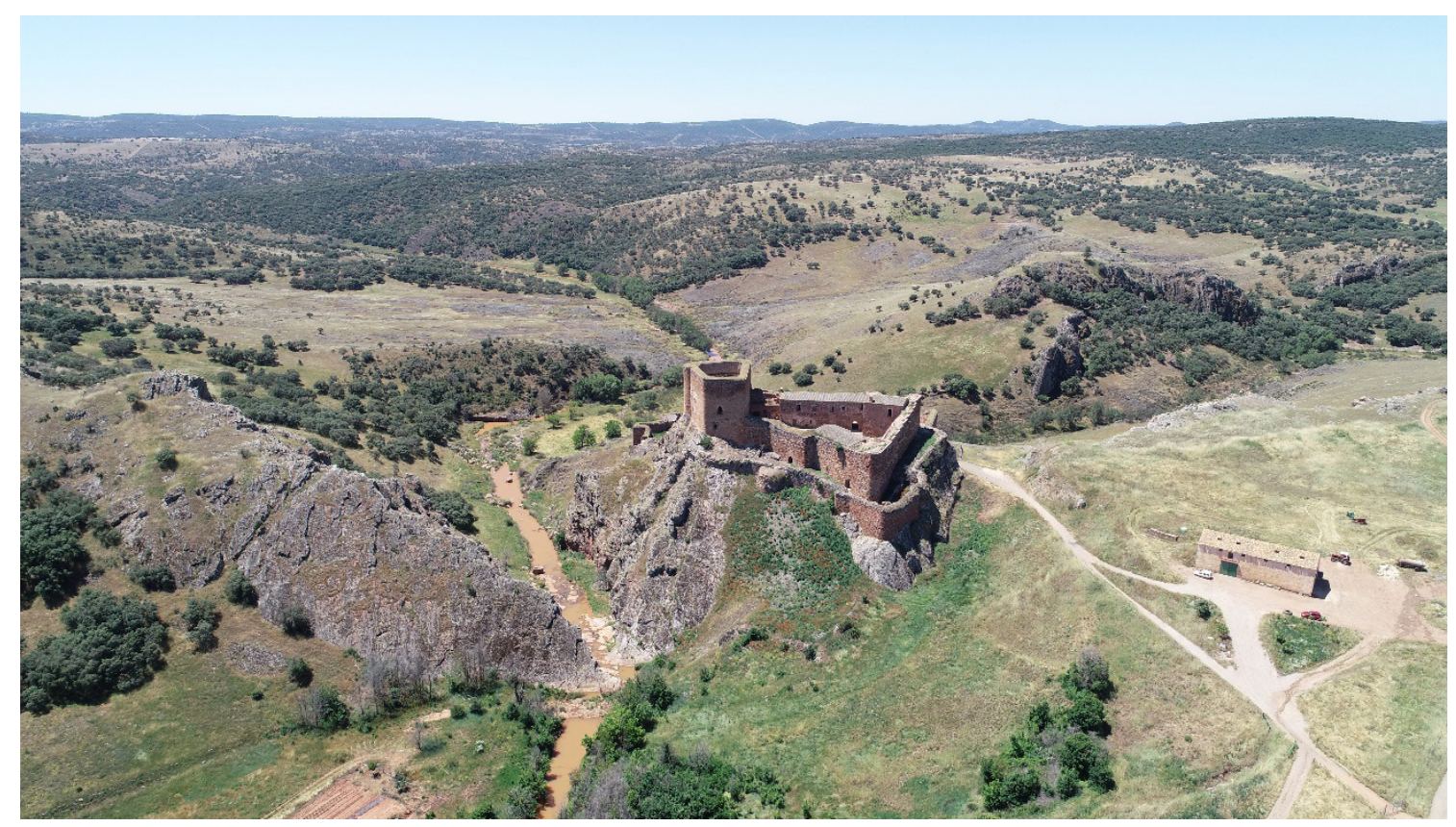

Tras analizar la morfología del castillo de Montizón, aunque haya sido de una forma somera, vemos que se trataba de un punto fuerte difícil de tomar por un asalto directo. En este sentido, se nos plantean dos cuestiones que nos parecen importantes: con qué guarnición y víveres contaba en esos momentos y, por otro lado, saber si la fortaleza tenía las suficientes armas para poder batir a los atacantes. El primero de estos interrogantes es difícil de responder al no existir información y los diversos estudios con los que contamos sobre las tropas acantonadas en los castillos de las órdenes militares (Ruiz, 2000; RodríguezPicavea, 2008: 136) no han podido dar datos definitorios, en especial para estos momentos tal convulsos (Palacios, 2018: 227-238; Rodríguez, 2019: 253-254). No obstante, desde nuestro punto de vista, creemos que esta plaza al estar situada en una posición precaria, rodeada de posesiones de los Manrique, debía haber sido reforzada con víveres y hombres y contaría, a grandes rasgos, con una tropa lo suficientemente numerosa para poder llevar a cabo una defensa efectiva del enclave, como así sucedió.

Montiel y Sierra de Segura. Castillo de Montizón, p. 270. 
Sobre la segunda de las cuestiones sí que tenemos una información más excelsa procedente de los libros de visita y del estudio arqueológico de la fortaleza. En este sentido, en $1478^{12}$, poco después de acabar el asedio, sabemos que el lugar contaba con armas de fuego y ballestería, elementos que, probablemente, ya estaban presentes antes y durante el cerco, en una realidad generalizada en el reino de Castilla (Castro y Mateos, 2018: 110112). Por otro lado tenemos datos procedentes del estudio estratigráfico de paramentos de que el castillo no poseía a penas estructuras artilleras para su defensa, salvo algunas troneras abiertas en el muro norte, hecho muy similar al que hemos identificado en los recintos militares de esta Orden en el entorno. Será tras la conquista de la plaza y las reformas que lleve a cabo Jorge Manrique ${ }^{13}$ cuando se dote al lugar de pequeñas cámaras de tiro y un cubo en el frente oriental, destinado este último a batir el paso del vado situado sobre el río Guadalén.

Analizado ya el panorama que encontraron las tropas rebeldes al inicio del cerco, nos es de extrañar que Pedro Manrique, comandante de la hueste, fuera prudente en la planificación de la expugnación. Esto no nos debe extrañar si tenemos en cuenta el duro correctivo que había sufrido frente a las murallas de Alcaraz sólo unas semanas antes, donde al intentar tomar por asalto el alcázar había perdido numerosos hombres, entre ellos su hermano Diego (Pretel, 1978: 129-130). Los datos contenidos en la Crónica sobre estos primeros momentos son prácticamente inexistentes, pero sabemos que los atacantes comenzaron a levantar un castillo padrastro en las cercanías ${ }^{14}$, que estudiaremos en detalle más adelante, al no claudicar rápidamente el enclave, desde el que podían controlar los accesos y los movimientos de los defensores en el acceso occidental a la fortaleza. En este punto fuerte dejaron un cuerpo de peones, así como pequeños retenes para el control de lugares estratégicos como era el paso del río Guadalén y los caminos que comunicaban, hacia el este, con Belmontejo y, al norte, con Torre de Juan Abad a través de la cañada de La Vega. Junto con estas tropas se crearon, además, varios cuerpos de caballería que debían impedir que llegaran suministros a los sitiados ${ }^{15}$, bloqueando por completo la plaza en una práctica habitual del paradigma bélico medieval (García, 2019: 167-169; Suñé, 2013: 118), hecho que será una de las pugnas fundamentales de este episodio y que será clave para la caída de esta posición.

El cerco se extendió a lo largo de prácticamente nueve meses sin que existieran avances significativos, entrando, hasta noviembre de 1465 , en un punto muerto. A esto contribuyó la figura del alcaide del castillo, Gómez de Álvarez, junto a otros personajes notables al servicio del Condestable, que durante esta etapa del asedio pudieron resistir sin grandes problemas. En esta horquilla de tiempo debieron producirse combates y los atacantes, aunque no se refiere a ello de forma explícita en el texto, intentaron ablandar las murallas mediante fuego artillero. En este sentido, por el estudio poliorcético que hemos llevado a cabo, sabemos que el único punto débil era el frente norte del antemuro y el paño del cuerpo de la fortaleza en este costado, que quedaban a tiro posicionando piezas artilleras sobre el cantil rocoso que se elevaba ligeramente al norte, en la zona donde actualmente existe un conjunto de elementos agrícolas.

12 Año de 1478. A.H.N., OO.MM., Libro 1063, Visita a los partidos de la Mancha, Ribera del Tajo, Campo de Montiel y Sierra de Segura. Castillo de Montizón, p. 274.

13 Año de 1468. A.H.N., OO.MM, Libro 1233, Visita a los partidos de la Mancha, Ribera del Tajo, Campo de Montiel y Sierra de Segura. Castillo de Montizón, p. 24.

14 Hechos del Condestable..., (ed. 2009, p. 298)

15 Historia de la Casa de Lara..., (ed. 1697, p. 333) 
Figura 3. Mapa de la visibilidad existente desde la fortaleza del Cerro de la Horca

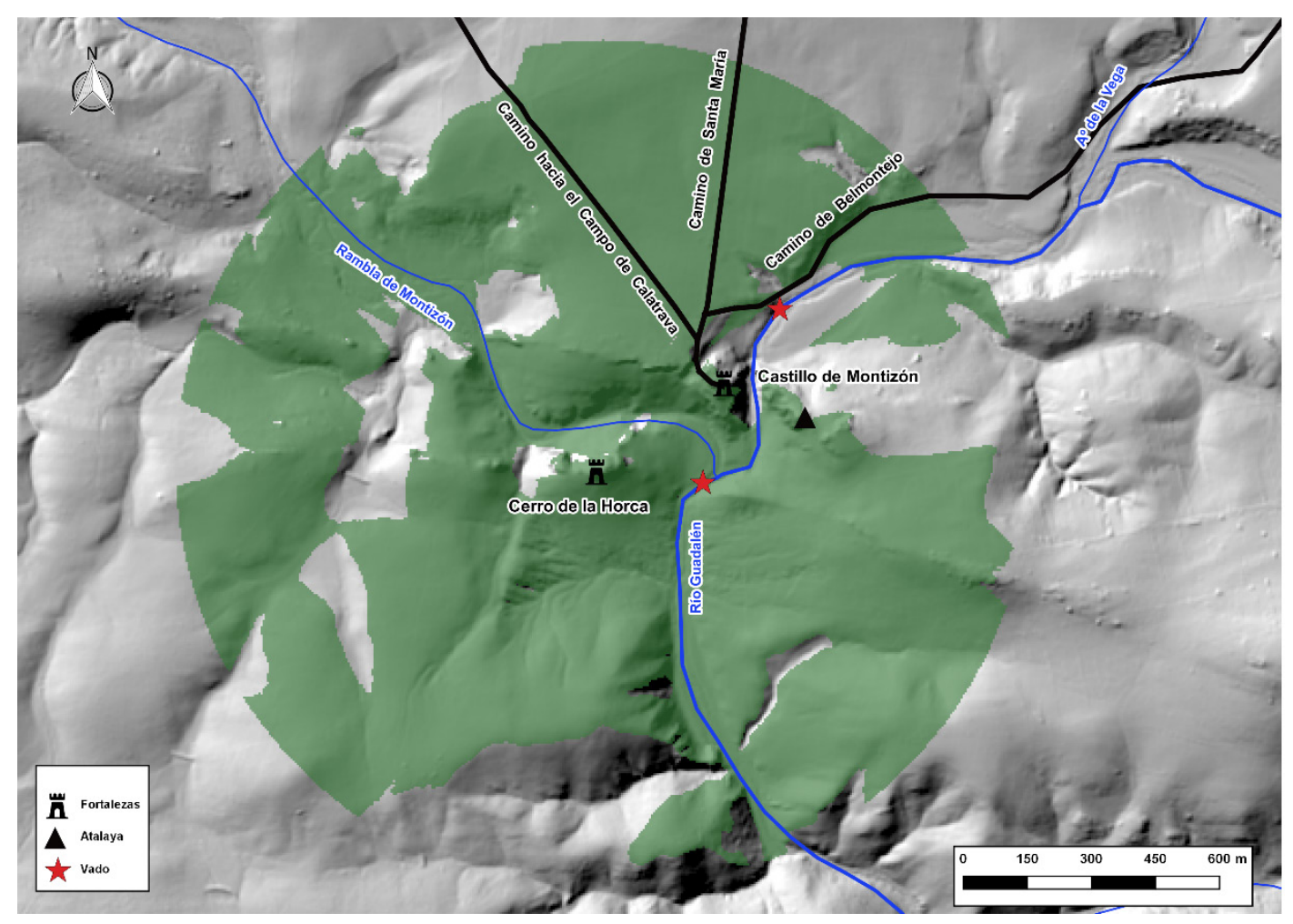

Figura 4. Disposición del cerco en torno a Montizón con los lugares descritos en el texto

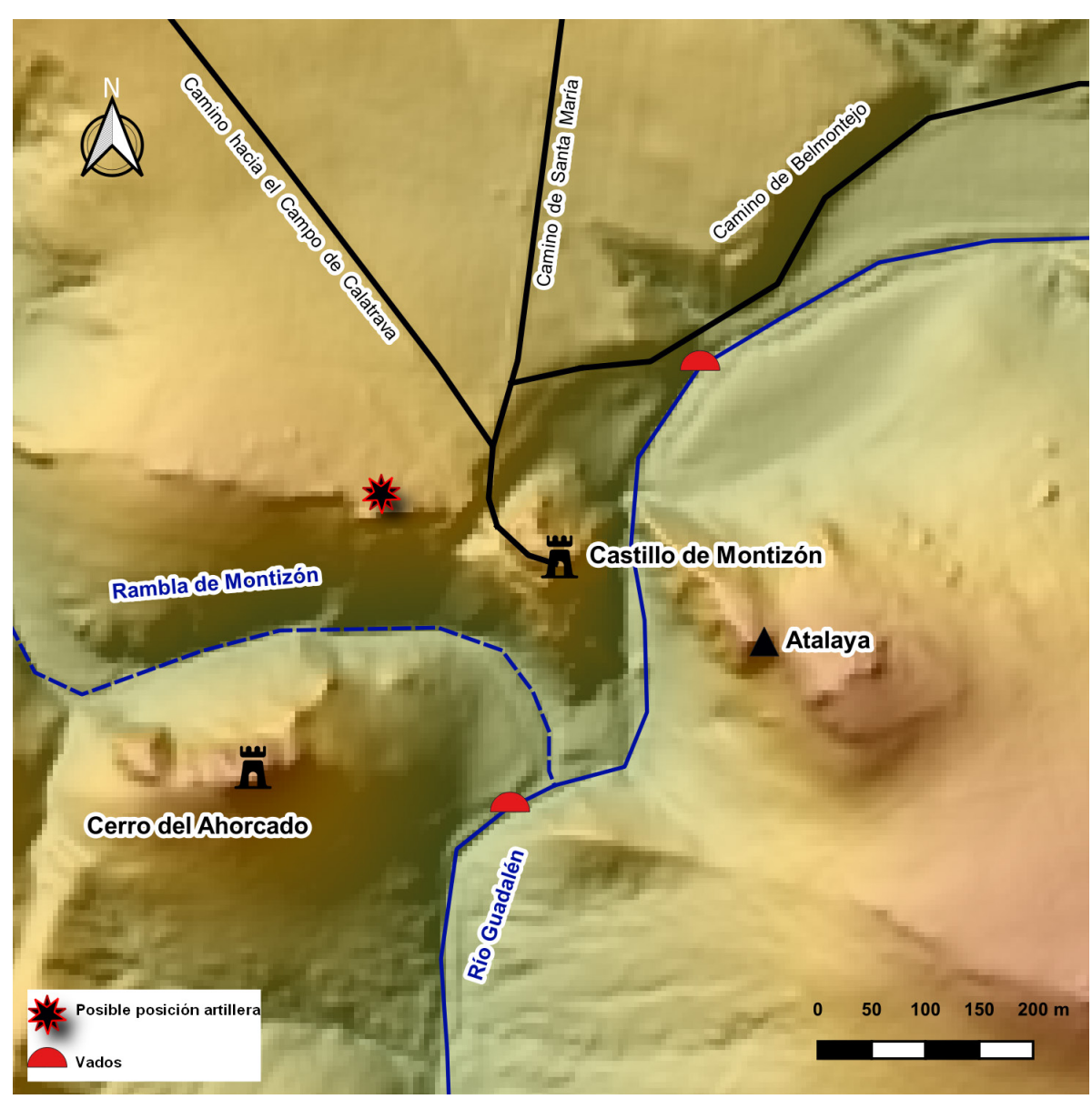


El uso de la artillería sobre los paños debió tener como consecuencia la destrucción de parte del costado norte del antemuro, lo que motivó un proceso de reconstrucción que hemos podido documentar estratigráficamente y que, claramente, se pueden asociar a la reforma que hace del castillo Jorge Manrique a partir de 1467 debido a que se encontraba “...mal reparado en algunos logares que se malparo quando el çerco del dicho castillo..."16. Estos "parches" se elaboraron con una piedra menuda y están localizados, principalmente, en la base del muro, lo que no nos debe extrañar, ya que, normalmente, la artillería atacante, con la falta de acierto que solía tener aún en estos momentos (Castro y Mateo, 2018), intentaba batir tanto la base como el remate de los muros con el fin de abrir brecha, en el primer caso, y dejar sin un parapeto efectivo a los defensores, en el segundo.

Figura 5. Castillo de Montizón desde la meseta situada al norte de este, donde se pudieron situar las piezas de artillería de los atacantes

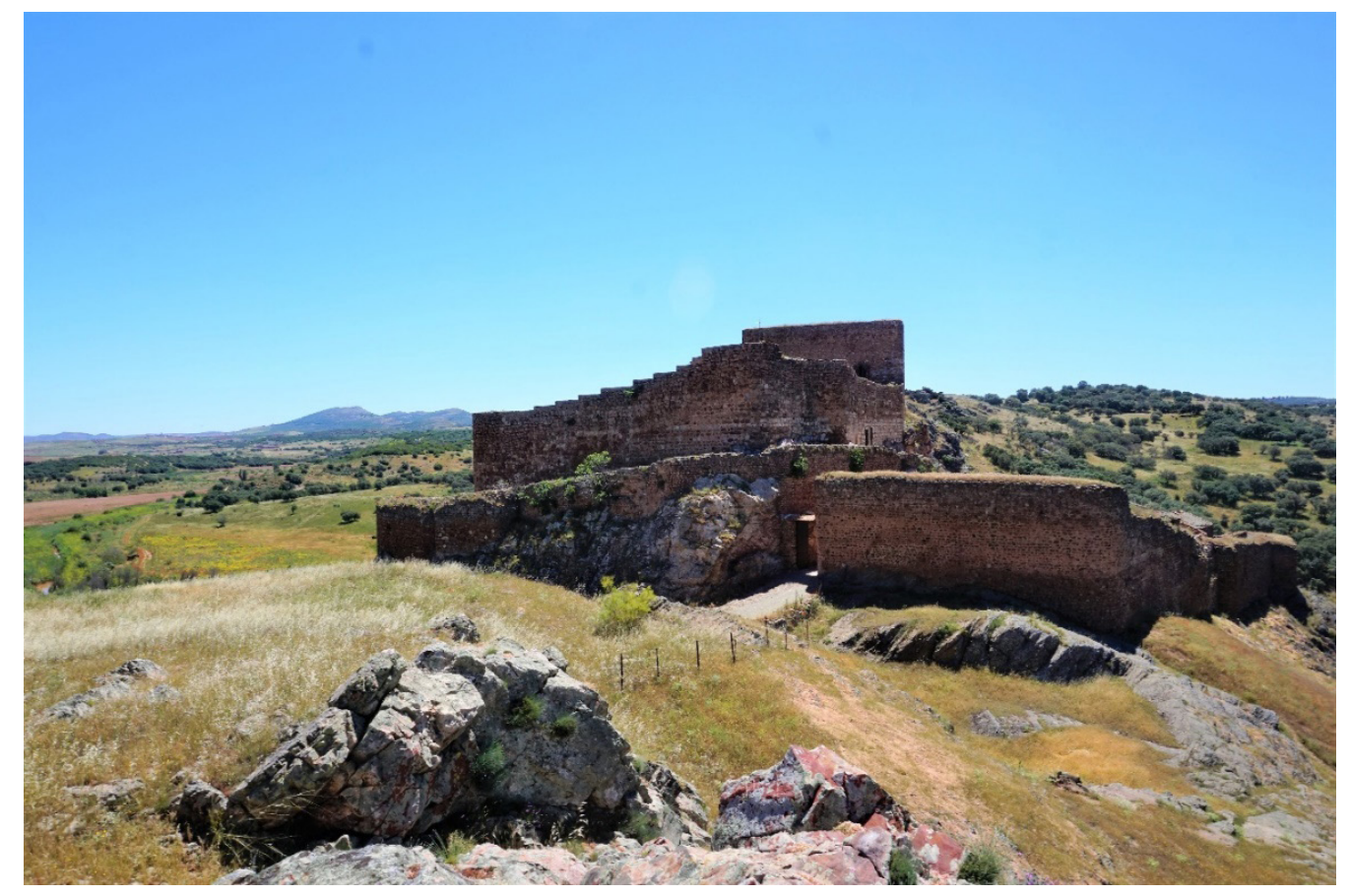

\subsection{El primer socorro de Montizón y el asalto al castillo padrastro del cerro de La Horca (octubre-noviembre de 1465)}

Hasta octubre de 1465 se hizo esperar una respuesta por parte del bando del Condestable que, durante parte de este año, tuvo que centrar sus esfuerzos en defender la ciudad de Jaén hasta la tregua firmada con el maestre calatravo Pedro Girón. Atajado, de momento, este frente, Miguel Lucas de Iranzo organizó una operación de rescate ante las constantes demandas del alcaide Gómez de Álvarez por la situación desesperada en la que se encontraba la guarnición “...que bien avía tres meses o más que non comían carne sino alguna carne de asnos...que le socorriese lo más presto que ser pudiese, porque estaba en asa trabajo..."17. En este sentido, como ya mencionamos, mientras los atacantes tenían unas sólidas bases logísticas en el entorno próximo desde las que podían abastecerse, en el caso del Condestable le era muy difícil hacer llegar una ayuda 
al estar controlados gran parte de los pasos de Sierra Morena por las tropas afines al bando rebelde del infante Alfonso.

El análisis de la caminería medieval de la zona, sobre la que ya trabajamos (Gallego, 2015), nos permite saber que existían cinco accesos posibles ${ }^{18}$, de oeste a este, para poder llevar el socorro hasta Montizón desde las posiciones de los Iranzo en Jaén: el Muradal, Torre Alver, el camino de Cuenca a Granada, la vía que unía Montiel con Segura de la Sierra $y$, finalmente, el acceso por el camino de Úbeda a Alicante en las proximidades de Alcaraz. El primero, el puerto del Muradal, se encontraba en esos momentos bien controlado por las tropas del maestre de Calatrava con el que, recientemente, se había firmado una tregua de la que no se fiaban los Iranzo. El siguiente, el cruce por el puerto de Torre Alver, era el más dificultoso de todos, tanto por la orografía como por la presencia de contingentes armados pertenecientes al señor de Santiesteban del Puerto ${ }^{19}$, contrario al bando del Condestable. Los tres últimos se encontraban en el corazón de las posesiones de los Manrique, lo que hacía inviable su uso sin caer en un encuentro armado que, muy probablemente, habría destruido a las tropas de los Iranzo.

El lugar elegido, finalmente, fue el paso de Torre Alver al que las tropas llegaron, tras recorrer el camino desde Jaén, el veintinueve de octubre. El contingente formado para la operación, que se llevó con gran secreto avanzando en jornadas nocturnas ${ }^{20}$, estaba al mando del comendador Diego de Iranzo pero no se detalla el número total de combatientes. Tradicionalmente, para atravesar Torre Alver, se solía cruzar la Sierra del Cambrón por su costado oriental, por la cañada ganadera, pero en ésta se hallaban establecidas tropas de los Manrique. Por este motivo, creemos que Diego de Iranzo prefirió usar un camino secundario, más escarpado, que se conocía ya en el siglo XIII y que pudo servir para el deslinde entre las órdenes de Santiago y Calatrava en 123921. Esta vía, cuyo trazado hemos documentado mediante una serie de estudios de $\mathrm{SIG}^{22}$, pudimos comprobar cómo era apta para las caballerías ${ }^{23}$ tras hacer la prospección de la zona. Su trazado discurre cercano a las ruinas del castillo de Torre Alver hasta atravesar Sierra Morena por el paso occidental de la Sierra del Cambrón, tras lo que se dirige hacia el cortijo de Navas de la Condesa, que deja al oeste, para unirse al actual camino de Castellar de Santiago a Montizón, por donde debieron llegar las tropas del Condestable hasta las proximidades de la fortaleza el día uno de noviembre. A partir de aquí se entabló un combate, que sorprendió a los Manrique, poniendo en fuga a sus tropas salvo las que se refugiaron en el castillo padrastro.

18 Corchado (1963: 9-40) en sus estudios ya clásicos, analizó de forma detallada el conjunto de pasos que existían desde Andalucía hacia las provincias de Ciudad Real y Jaén. Sobre el mismo tema ha trabajado Castillo (2001: 49-104), en especial para la vertiente sur de Sierra Morena

19 Historia Genealógica de la Casa de Lara..., (ed. 1697)

20 Hechos del Condestable..., (ed. 2009, p. 297-301)

21 Año de 1239. Doc. publ. Rivera Garretas (1985: 385, doc. 183)

22 Para el estudio de las diversas rutas ideales hemos utilizado el módulo de GRASS integrado en QGIS 3.4.

23 Dejando de lado los jinetes, creemos que las acémilas con su carga, que fueron las encargas de llevar los pertrechos como era costumbre en tierras castellanas hasta ese momento (Ladero, 2010: 292), pudieron pasar sin dificultad por esta zona. 
Figura 6. Cálculo de la ruta ideal para conectar la vía al pie de Torre Alver con el castillo de Montizón

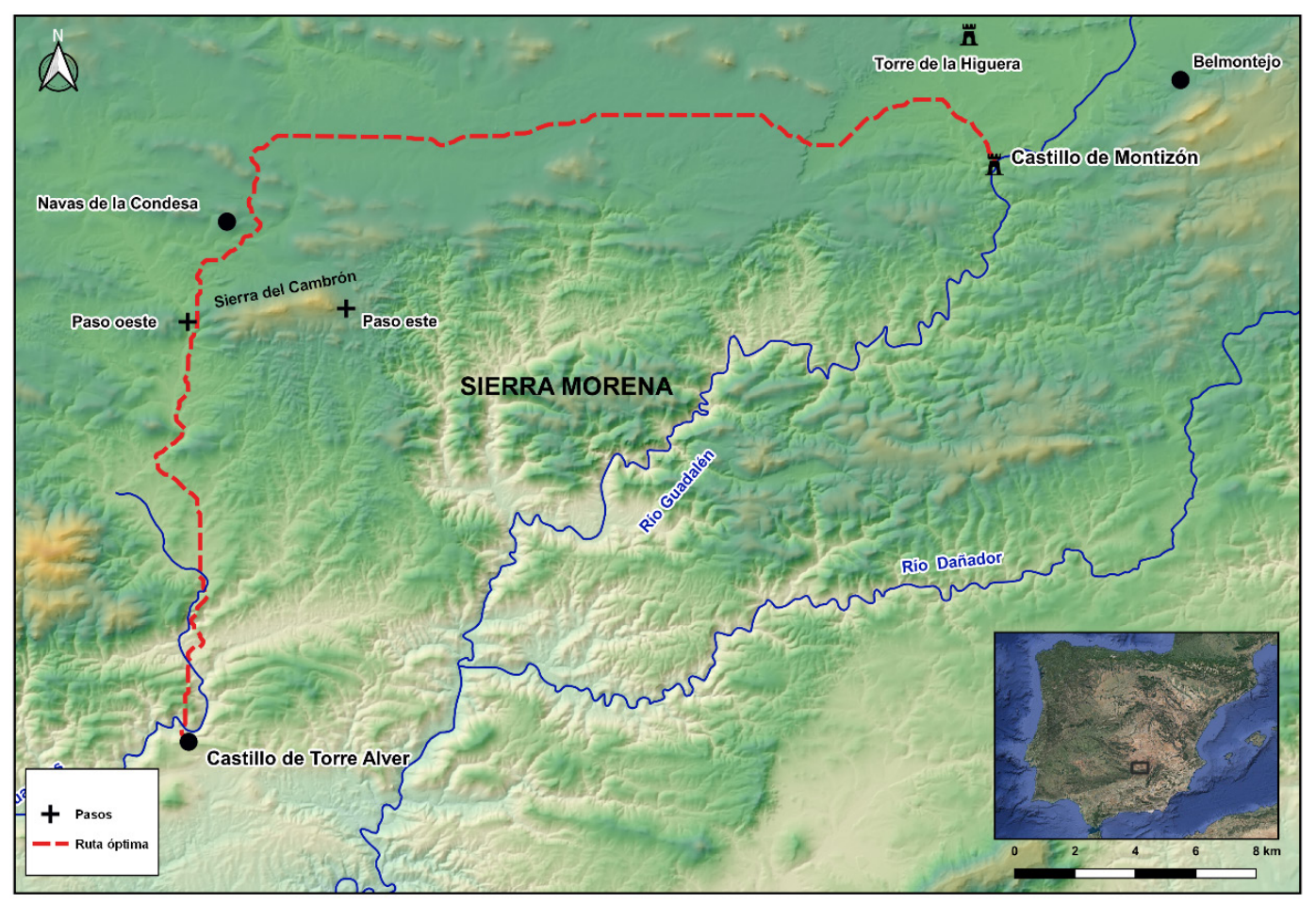

Figura 7. Pasos de Sierra Morena por el itinerario de Torre Alver

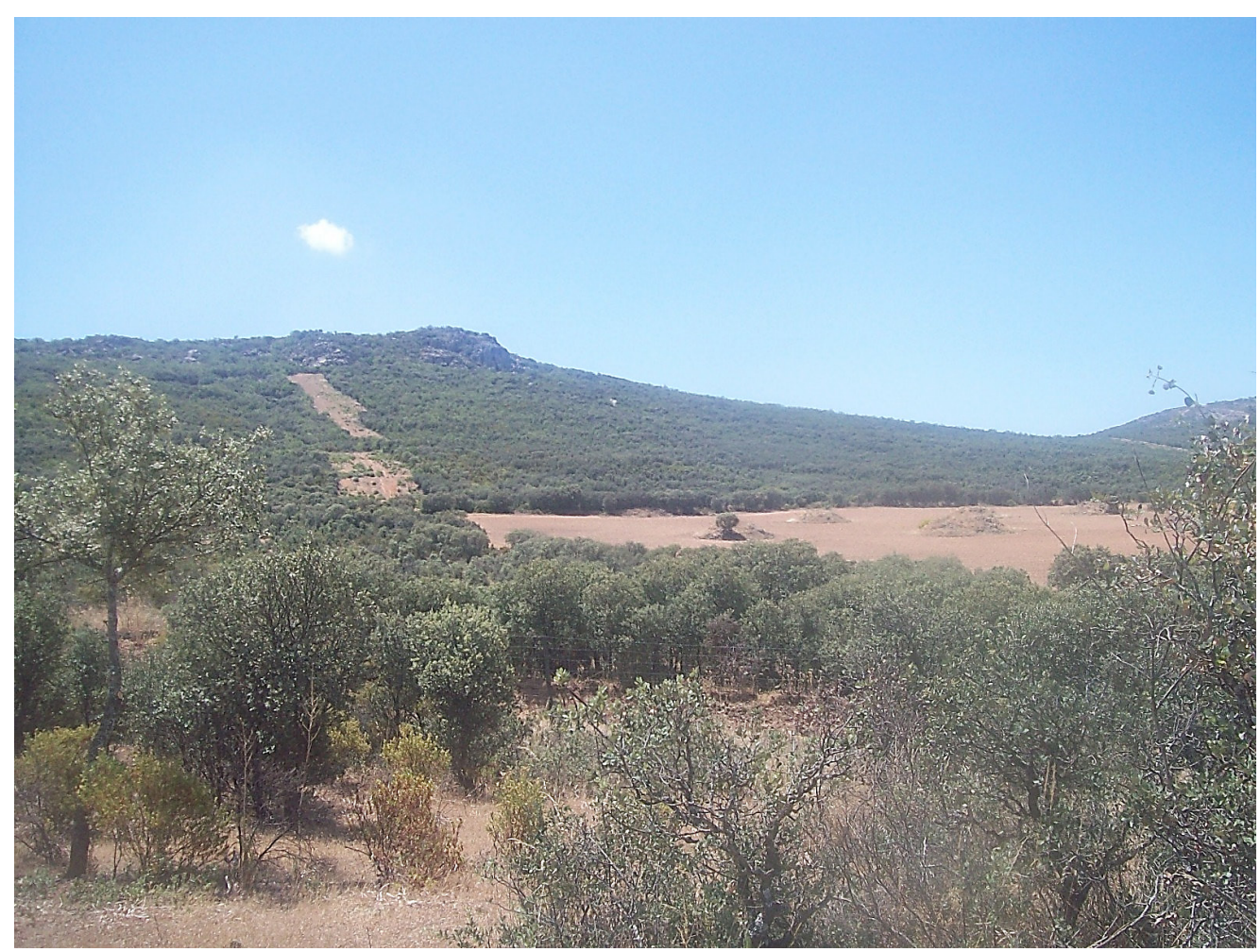


Una vez que se reunieron las tropas del socorro y el contingente que defendía la fortaleza, se describe en la Crónica lo que debió ser el principal hecho de armas de todo el asedio, el asalto al castillo padrastro. El lugar, en los Hechos del Condestable, se nos cita como había sido construido "... en un cerro que estaba çerca e bien junto con el dicho castillo, de la otra parte de un río o arroyo que por allí pasaua..."24. Este recinto fortificado, hasta la fecha, no había sido identificado en las diversas publicaciones que citamos anteriormente. Por ello, con los datos de las fuentes escritas, comenzamos un estudio arqueológico que tuvo dos fases. En primer lugar, nos centramos en consultar la cartografía histórica, así como en analizar los diversos cerros que rodeaban el castillo realizando, en aquellos que podían corresponderse con el enclave citado, un análisis LIDAR con el fin de documentar posibles estructuras. En segundo lugar, llevamos a cabo la prospección arqueológica de campo, tanto extensiva como intensiva, donde identificamos los puntos que reunían las condiciones necesarias para poder ubicar la fortaleza de la Crónica: estar ubicado al otro lado del río con respecto a Montizón, contar con un control visual importante, tanto sobre la plaza asediada como sobre las vías de comunicación, y que tuviera unas defensas naturales de cierta entidad.

Finalmente, pudimos documentar dos lugares que reunían las condiciones. En el primero, en el cerro de Los Collados, ubicado en una elevación de 802 m, al sur de Montizón, identificamos los restos de un poblamiento prehistórico de cierta entidad así como materiales de cronología medieval. Estos últimos creemos que pueden estar asociados con una pequeña atalaya relacionada con la defensa del castillo de Montizón pero que, durante el asedio, estuvo en manos de los atacantes como punto de control del vado oriental del río Guadalén. El segundo, el denominado como cerro de La Horca o del Árbol del Ahorcado, está localizado al oeste de nuestra fortaleza, al otro lado del arroyo de Montizón, siendo una posición defensiva de gran entidad donde documentamos vestigios de un recinto con hasta tres fases cronológicas. La primera se correspondía con una gran ocupación prehistórica; la segunda estaba asociada a una fortaleza de época andalusí; y la tercera la identificamos con el castillo "padrastro" que nos citan las fuentes durante el asedio.

Figura 8. Vista desde Los Collados del castillo de Montizón y, a la izquierda, el cerro de La Horca

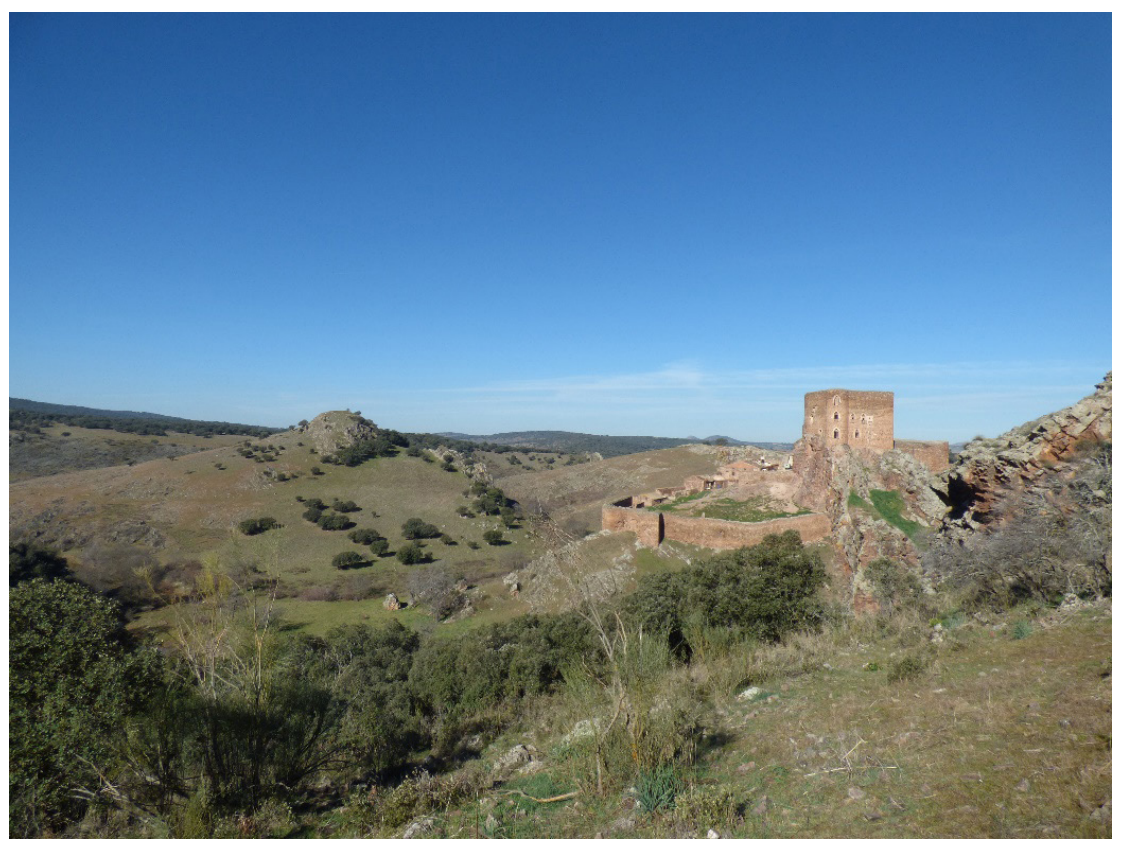

24 Hechos del Condestable..., (ed. 2009, p. 300) 
El cerro de La Horca presentaba, por tanto, una posición geoestratégica muy interesante ya que su campo de visión controla tanto el castillo como los puntos de acceso hasta el mismo, complementado por la atalaya de Los Collados, a la vez que, psicológicamente, marcaba una posición preeminente a la vista de los asediados. La construcción de este punto fuerte por parte de los Manrique aprovechó, por tanto, las ruinas de un edificio islámico en el que se recreció el antemuro para levantar una cerca baja que rodeaba por completo el espacio superior, salvo el costado septentrional donde existe un gran acantilado formado por el paso del arroyo de Montizón. Por otro lado, el recinto principal, que tiene un origen andalusí, describe una planta rectangular de aproximadamente $300 \mathrm{~m}^{2}$, formada por muros de mampostería de cuarcita, lo que coincide con la descripción de la Crónica, que alcanzan $1 \mathrm{~m}$ de anchura. La envergadura del edificio resultante posee una superficie lo suficientemente amplia para albergar un contingente de tropas acantonadas donde incluso existían una serie de "...casas que tenían dentro fechas..." 25 . Por otro lado, el registro material apunta también a la hipótesis que planteamos ya que, en la superficie del yacimiento, documentamos cerámicas de esta fase, especialmente algunas lozas, así como una serie de elementos metálicos relacionados con las caballerías y numerosos clavos.

Figura 9. Planta de la fortaleza del Cerro de la Horca

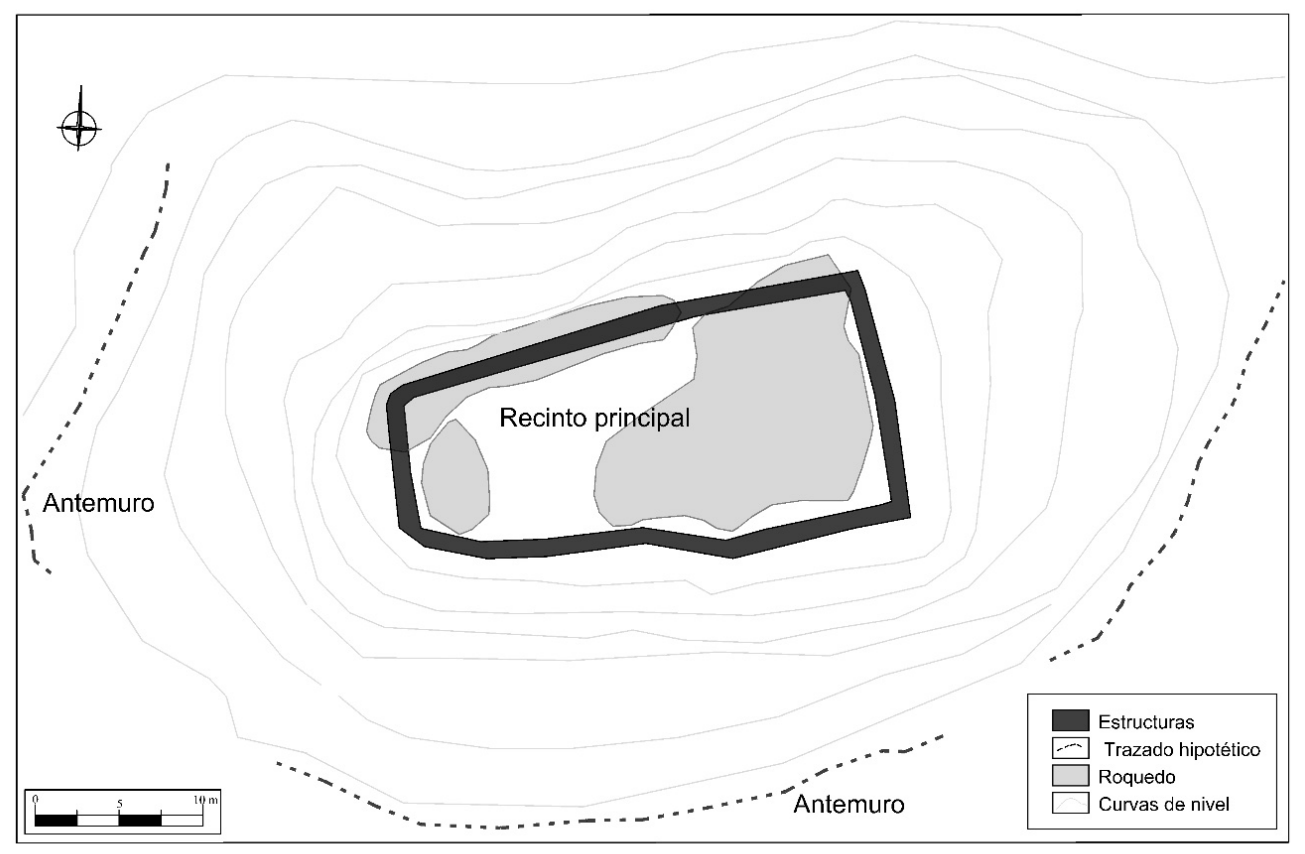

25 Hechos del Condestable..., (ed. 2009, p. 300) 
Figura 10. Vestigios de la muralla perimetral de la fortaleza superior

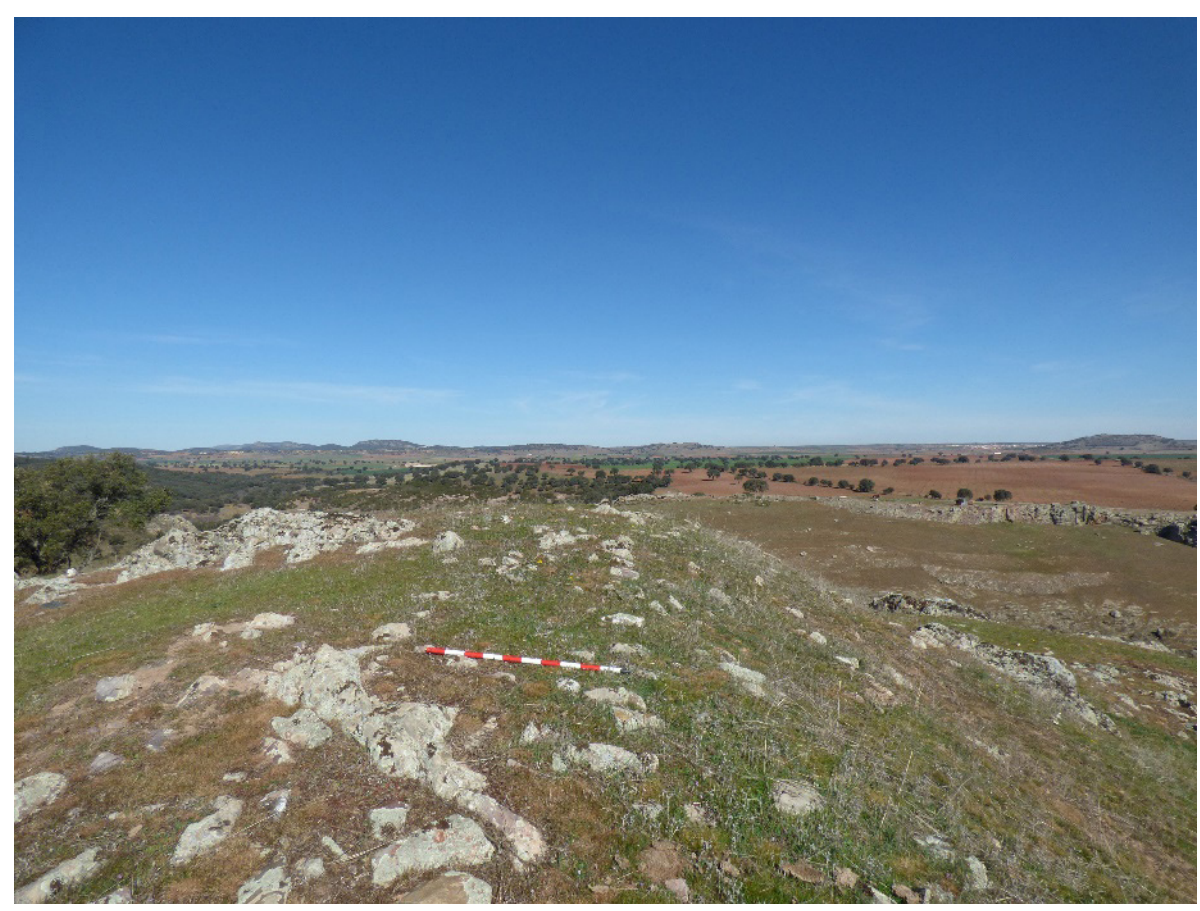

Volviendo al desarrollo de los hechos, de cara a expugnar esta posición, los Iranzo prepararon un asalto en toda regla que debía tomar el enclave por varios frentes, exceptuando la zona norte que era inviable por su topografía. Dentro del contingente que llevó a cabo el ataque se nos cita la presencia de ballesteros con paveses y espingarderos, procedentes de la hueste del propio castillo, así como peones y la caballería de la tropa del socorro, a la que se mandó desmontar. El hecho de armas debió ser relativamente rápido y violento, pues se nos narra que los defensores arrojaron muchas "... piedras e ballestas e muchas lanzas..." 26 , lo que provocó un importante número de bajas entre los Iranzo aunque, finalmente, la fortaleza fue tomada y el lugar saqueado obteniendo un suculento botín de prisioneros, armas, caballos y ganado. Tras esto, aunque no se cita expresamente, el edificio debió ser desmochado, lo que explicaría el nivel de arrasamiento que presenta en la actualidad.

Una vez finalizada la contienda, Montizón fue abastecido de pertrechos y nuevos hombres, tras lo que el comendador Diego de Iranzo organizó el regreso a tierras de Jaén. El trayecto de vuelta no fue fácil, ya que los Manrique y sus aliados sabían de lo ocurrido y habían cerrado los pasos, entre ellos el utilizado anteriormente por Torre Alver. Finalmente, en una cabalgada apresurada la hueste del Condestable cruzó hacia tierras andaluzas por el puerto del Muradal, con cierta preocupación ante la posibilidad de que el maestre de Calatrava rompiera las treguas y le atacara, algo que finalmente no sucedió y pudo llegar hasta la ciudad de Jaén. 
Figura 11. Mapa de los movimientos de las tropas en 1465

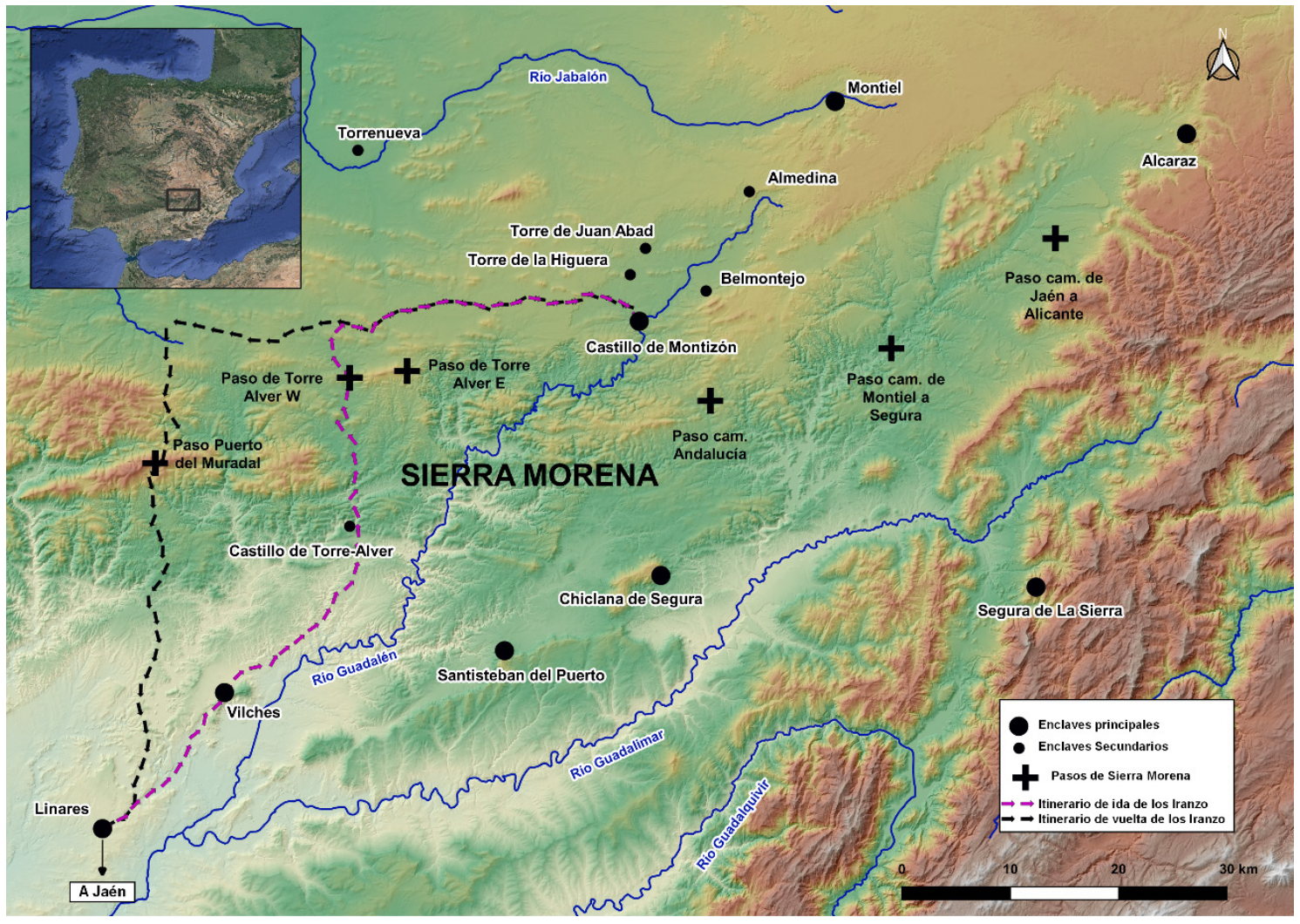

\subsection{La guerra de posiciones y la capitulación de la fortaleza (1466-1467)}

Poco tiempo después de la partida del comendador de Montizón, posiblemente en la primera mitad de 1466, el castillo volvió a ser asediado por parte de Pedro Manrique, aunque en este caso la táctica elegida, que culminará con la toma de la fortaleza, será la de bloquear la plaza y hostigarla hasta su rendición. Esta estrategia, muy común en la guerra medieval (García, 2019), era fácil de aplicar en este contexto, pues el enclave estaba situado en una posición totalmente rodeada de posiciones enemigas. Para poder controlar mejor las operaciones, en esta ocasión, Pedro Manrique decidió situar su centro logístico en el cercano lugar de Belmontejo (futuro Villamanrique), viendo los malos resultados que le había dado retirarse hasta Segura de la Sierra el año anterior.

Tras varios meses de cerco ${ }^{27}$, a principios del mes de agosto, el Condestable organizó un nuevo ejército para socorrer la fortaleza que, además, trataría de realizar una cabalgada para asolar las posiciones de los Manrique. En este sentido, el comendador de Montizón partió de Jaén con doscientos cincuenta hombres a caballo y cien peones, a los que se sumó el alcaide de Andújar, Pedro de Esquivias, con otros cien jinetes y ciento veinte peones a los que seguía una recua de mulas con el abastecimiento ${ }^{28}$. El contingente, en esta ocasión, cruzó por el puerto del Muradal y varios días después llegó a Montizón, donde no encontró apenas resistencia y se pudo abastecer la fortaleza. A partir de aquí, las tropas de los Iranzo comenzaron a hacer una serie de operaciones que tenían dos objetivos. El primero era devastar la tierra y las aldeas del entorno, pertenecientes a los Manrique, con el fin de ir minando sus recursos. En segundo lugar, se intentó que, como consecuencia de 
Ios saqueos, Pedro Manrique reaccionara y se produjera un hecho armado entre ambas huestes, sabiendo de la superioridad numérica de los Iranzo en este momento. Para ello Diego de Iranzo atacó el lugar de Belmontejo, que saquearon, de donde consiguió escapar Pedro Manrique a la villa de Almedina hasta donde lo persiguieron, pero fueron detenidos ante las murallas de la villa, que esa época aún tenían una cierta entidad (Gallego, 2016).

Tras completar estas acciones de depredación, las tropas de los Iranzo volvieron hacia Jaén por el camino que habían traído días atrás desde Montizón. Su recorrido los llevó muy cerca del lugar de Torrenueva, que atacaron y saquearon, ya que el enclave pertenecía a la Encomienda Mayor de Castilla de la orden de Santiago, cuyo comendador era Gabriel Manrique. De este hecho, al que también se refiere Rubio (2017), tenemos constancia arqueológica a través de la prospección que realizamos en el entorno del santuario de la Virgen de La Cabeza, solar primitivo donde se asentaba la población (Figura 12). El material cerámico recuperado muestra cómo existe un importante hiato poblacional a partir de fines de la Edad Media, lo que se correspondería con el abandono violento de este asentamiento a favor del lugar actual del municipio, hecho que también se refiere en la visitación de Torrenueva en $1494^{29}$. A partir de aquí las tropas de los Iranzo se dirigieron al Muradal donde sufrieron una pequeña emboscada por parte de una patrulla perteneciente a los Manrique, que habían movilizado un pequeño ejército, aunque finalmente pudieron regresar a Jaén ${ }^{30}$.

Figura 12. Mapa del movimiento de tropas durante 1466

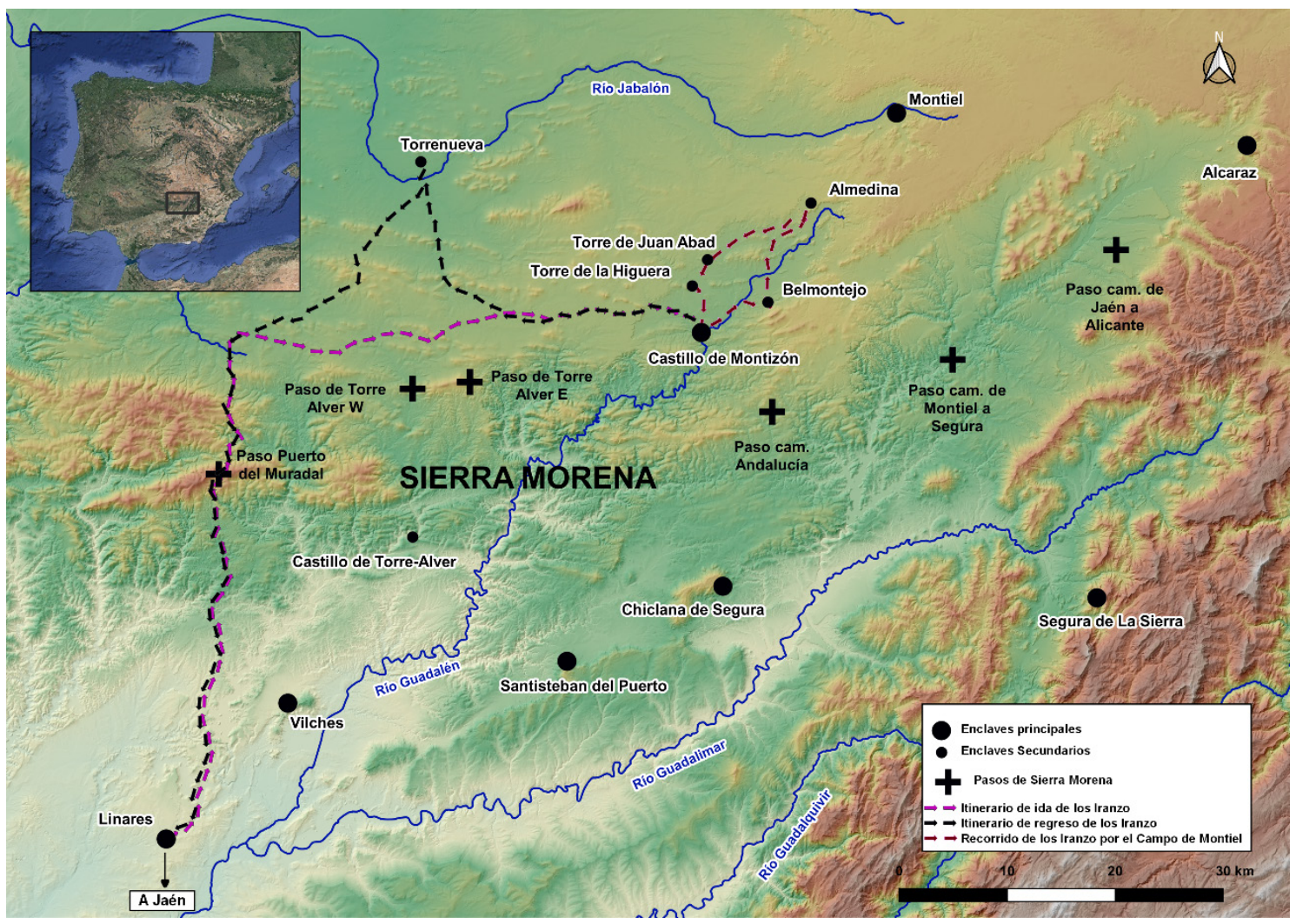

29 Año de 1494. A.H.N., O.O.M.M. Libro 1067, Visita a los partidos de la Mancha, Ribera del Tajo, Campo de Montiel y Sierra de Segura. Torrenueva, p. 638.

30 Hechos del Condestable..., (ed. 2009, p. 320) 
Figura 13. Vista general de la primitiva ubicación de Torrenueva, en el actual Santuario de la Virgen de la Cabeza

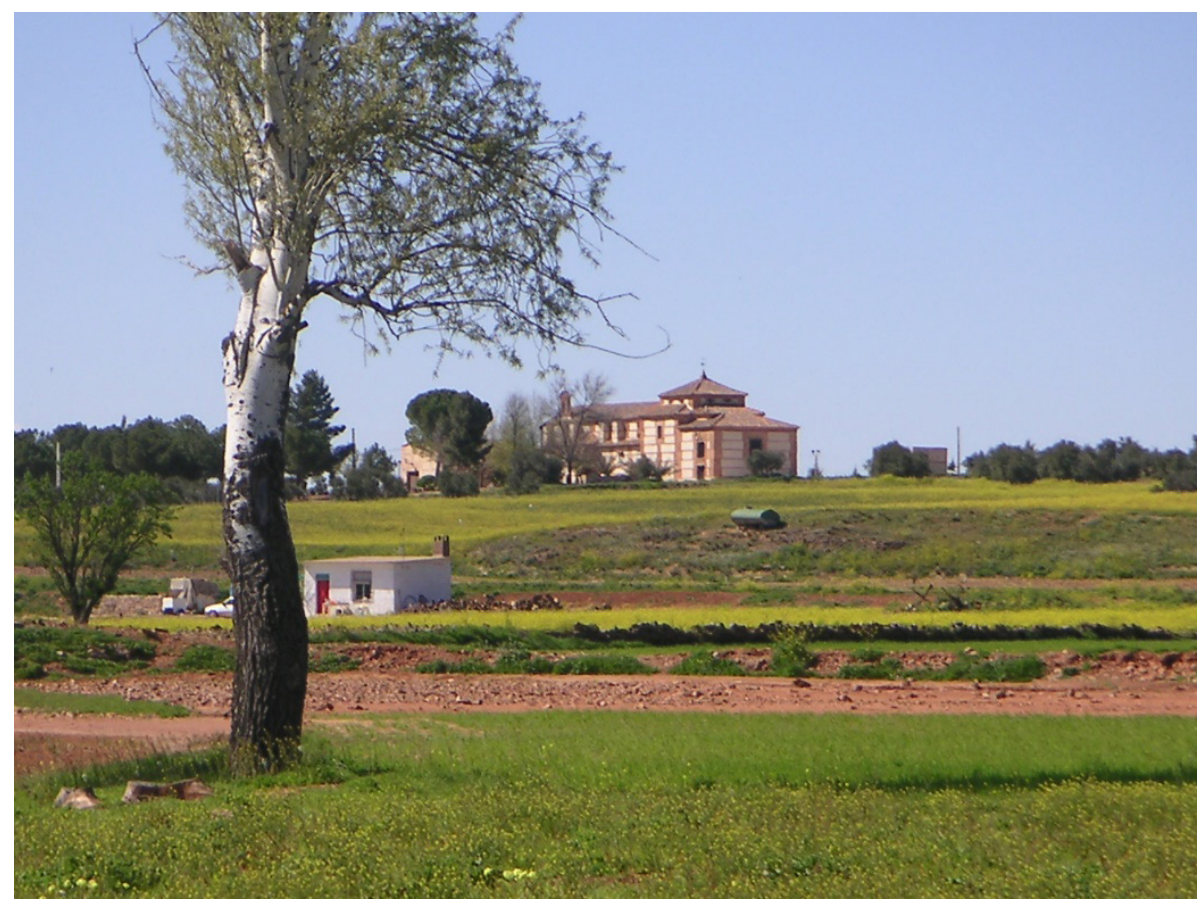

Bien es verdad que estas operaciones tuvieron un alcance limitado pues, en 1467, el castillo volvió a ser bloqueado y los Manrique ocuparon, nuevamente, sus posiciones en torno a la fortaleza. Es aquí donde comenzaron los contactos diplomáticos entre ambos bandos de cara a poner fin a una situación que se empezaba a tornar desesperada para los asediados. En este sentido, se llegó a un acuerdo entre Pedro Manrique y el alcaide Gómez Álvarez para “...aplazar el castillo..."31. Esta fórmula, bien conocida en los usos de la guerra medieval, consistía en que los defensores pudieran pedir un auxilio para que llegase una fuerza armada en su rescate. Si en el plazo establecido esta hueste no se presentaba en la plaza asediada, los defensores se comprometían a su rendición. Tras llegarle las noticias, el Condestable mandó formar un importante ejército que se concentró en Baños de La Encina para, posteriormente, cruzar por el puerto del Muradal siguiendo la ruta de $1466^{32}$. Por su parte, los Manrique comenzaron, siempre según la Crónica, a reunir una tropa de cierta entidad que debía llegar hasta Montizón para presentar, si fuera necesario, batalla campal a las tropas de los Iranzo, quizás en un acto de resarcimiento por la derrota de Olmedo del año anterior.

Bien es verdad que esto último no se llegó a cumplir pues, finalmente, al retrasarse el socorro el castillo se rindió y, tiempo después, encontramos a Jorge Manrique al frente de la encomienda de Montizón tras rendir obediencia al nuevo maestre santiaguista, Juan Pacheco. El insigne poeta estará al frente la misma hasta su muerte en 1478, momento en que comenzará un nuevo litigio por su posesión entre Diego de Iranzo y su hijo Luis, pleito que será arbitrado por Roma en 1494 a favor de los Manrique (Mercado, 1995b: 108).

31 Hechos del Condestable..., (ed. 2009, p. 318-320)

32 En su análisis de la Crónica Martín (2010: 69) cree que en ningún momento el Condestable tuvo intención de socorrer la plaza y que el cronista se esfuerza en justificar su abandono. 


\section{CONCLUSIONES}

A lo largo de este texto hemos querido reconstruir la materialidad del conflicto armado que se produjo en torno a la lucha por el control del castillo de Montizón, en particular, y de las posesiones de la orden de Santiago, en general, que se enmarcó en la guerra civil castellana que se dio entre Enrique IV y el infante Alfonso, al que apoyaba gran parte de la nobleza, por el control de la Corona entre 1465 y 1468 . En este sentido, hemos comprobado que combinando el análisis de las diversas fuentes documentales, tanto las crónicas como los libros de visitación, con los trabajos arqueológicos, se pueden estudiar físicamente los lugares citados, lo que permite hace una revisión crítica de la evolución de los hechos que, en unas ocasiones, apoya la versión que hasta el momento se tenía y, en otras, nos permite establecer nuevas hipótesis.

Durante este trabajo hemos aportado, gracias a las diversas herramientas arqueológicas que hemos aplicado, importantes novedades sobre el cerco a la fortaleza y las operaciones militares que se realizaron en torno al mismo. En primer lugar, las prospecciones a diversa escala nos han permitido localizar una nueva fortaleza que se desconocía hasta el momento, el cerro de La Horca, y que es uno de los pocos ejemplos de castillos padrastros de los que se tienen evidencias físicas. En segundo lugar, los resultados del estudio estratigráfico de paramentos nos han mostrado pruebas materiales de la destrucción que sufrieron los muros de Montizón durante este conflicto, lo que llevó a Jorge Manrique, tras asumir la encomienda, a realizar importantes trabajos de reconstrucción y de adaptación artillera de sus defensas. En tercero, gracias a la aplicación de los SIG hemos identificado diversos aspectos como el control que tenía el cerro de la Horca sobre Montizón o localizar los itinerarios que siguieron los ejércitos durante las campañas llevadas a cabo para romper el cerco destacando, entre estos, el paso desde Torre Alver a las Navas de La Condesa.

Los buenos resultados que, hasta el momento, nos está proporcionando la metodología de trabajo que hemos desarrollado para el estudio de la materialidad de la guerra medieval, que hemos aplicado tanto en Montiel como en Montizón y estamos comenzando a trabajar en Uclés o Salvatierra, nos hace ser optimistas de cara al futuro. En este sentido, como ya han mostrado otros equipos para periodos históricos muy diversos, la aplicación de una forma generalizada de la denominada "arqueología del conflicto" para el estudio de la guerra se está convirtiendo en una herramienta fundamental. Es más, para periodos como la Edad Media, donde no siempre contamos con una información histórica detallada, el análisis material de los hechos de armas nos permite aportar nuevas interpretaciones que, en algunos casos, llevaran a hacer una revisión crítica de estos episodios bélicos.

\section{BIBLIOGRAFÍA}

Arias, F. (2018), "Il Late Middle Ages (14th to 15th Centuries)", en F. García y J. Gouveia (eds.), War in the Iberian Peninsula, 700-1600, Abingdon, Routlegle, pp. 94-124.

Ayala, C. (1997), "La corona de Castilla y la incorporación de los maestrazgos", Militarium Ordinum Analecta, 1, pp. 259-290.

Bellón, J. P. et al. (2004), "Baecula, arqueología de una batalla", en A. Gálvez del Postigo (coord.), Proyectos de investigación (2002-2003), Jaén, Universidad de Jaén, pp. 11-66.

Calzado, M. P. (ed.) (2016), Tumbo Menor de Castilla (siglo XIII). Estudio Histórico, Codicológico, Diplomático y Edición, Cuenca, Universidad de Castilla-La Mancha.

Carceller, M. P. (2006), "Los bandos nobiliarios y la carrera política: ascenso y privanza de Beltrán de La Cueva", Anuario de Estudios Medievales, 36 (2), pp. 783-801.

Castro, J. J. y Mateo, J. (2018), "La artillería en el reino de Castilla y León durante el siglo XV", GLADIUS, XXXVIII, pp. 99-124. 
Castillo, J. C. (2001), "Las vías de comunicación terrestres entre Al-Ándalus y Castilla. Algunas propuestas para su estudio", La formación del espacio histórico: transportes y comunicaciones, Salamanca, Universidad de Salamanca, pp. 49-104.

Cooper, E. (1991), Castillos señoriales de la corona de Castilla, Salamanca, Junta de Comunidades de Castilla y León, 3 vol.

Corchado, M. (1971), "Pasos naturales y antiguos caminos entre Jaén y La Mancha", Boletín del Instituto de Estudios Giennenses, 38, pp. 9-40.

Curry, A. (2005), The battle of Angicourt, Londres, Tempus.

Echevarria, A. (2004), "Enrique IV de Castilla, un rey cruzado", Espacio, Tiempo y Forma, Serie III, $H^{a}$ Medieval, 17, pp. 143-156.

Etxeberria, E. (2019), "El liderazgo militar en la Castilla del siglo XV", Hispania, LXXIX, 263, pp. 639-668.

Fernández-Pacheco, C. y Moya, C. (2015), "El sistema defensivo del Campo de Montiel, en la segunda mitad del siglo XV", Revista De Estudios Del Campo De Montiel, 4, pp.183225.

Gallego, D. (2015), "Del emirato a la conquista cristiana: propuesta de reconstrucción del paisaje histórico del Campo de Montiel (ss. IX-XIII)", Revista de Estudios del Campo de Montiel, Extra 1, pp. 9-53.

- (2016), "La fortificación medieval en el Campo de Montiel (ss. VIII-XVI). Análisis de su secuencia histórica y constructiva", Espacio, tiempo y forma. Serie III, $H^{a}$ medieval, 29, pp. 337-376.

- (2020), Las fortificaciones del Campo de Montiel (ss. VIII al XVI): historia, arqueología y análisis constructivo, Tesis doctoral s.p., Universidad de Castilla- La Mancha.

García, F. (2019), La guerra contra el Islam peninsular en la Edad Media, Madrid, Sílex.

García, F. y Novoa, F. (2018), "El papel militar de las Órdenes Militares en los conflictos civiles castellanos del siglo XV", en I. C. Ferreira, (coord.), Entre Deus e o Rei. O mundo das Ordens Militares, Palmela, Municipio de Palmela, vol. II, pp. 371-390.

Hechos Del Condestable Lucas De Iranzo (Crónica del siglo XV) (ed. 2009), Edición a cargo de J. Mata, Madrid, Marcial Pons.

Gomes, M. (2016), Guerreiros de pedra. Castelos, muralhas e guerra de cerco em Portugal na Idade Média, Lisboa, La Esfera de los Libros.

Hervás, M. A. y Retuerce, M., "Calatrava la Vieja. De medina a encomienda", en Mil Anos de Fortificaçoes Na Península Ibérica E No Magreb. (500-1500), Actas Do Simposio Internacional Sobre Castelos (2002), Lisboa, Ediçoes Colibri, pp. 311-317.

Ladero, M. A. (2010), "La Baja Edad Media", en M. A. Ladero (coord.), Historia Militar de España, Edad Media, Madrid, Ministerio de Defensa, pp. 217-378.

Lech, W. (2014), "Castle at war. Archaeological records of fighting during the siege of Castle Kolno in Silesia", Forschungen zur Archäologie im Land Brandenburg, 15, pp. 131-144.

Livinsgton, M. y Drevies, K. (2015), The Battle of Crécy: a Casebook, Liverpool, Liverpool Historical Casebooks.

Madrid, A. (1988), "Jorge Manrique, comendador de Montizón", Cuadernos de Estudios Manchegos, 18, pp. 327-340.

Martín, J.J. (2010), "Miguel Lucas ante Enrique IV. Desobediencia y lealtad en los Hechos del condestable Iranzo", Boletín de la Biblioteca de Menéndez Pelayo, L LXXVI, pp. 47-81

Martín, J. L. (2003), Enrique IV de Castilla, rey de navarra, príncipe de Cataluña, Hondarribia. Nerea.

Mercado, J. (1995a), "La Encomienda de Montizón y Chiclana (Orden de Santiago)", Boletín del Instituto de Estudios Giennenses, pp. 115-194. 
- (1995b), "Los comendadores de Montizón y Chiclana (Orden de Santiago)", Boletín del Instituto de Estudios Giennenses, pp. 91-176.

Molero, J. M. (2005), "Los castillos-casas de la encomienda en el Campo de Calatrava", en A. Ruibal (coord.), Actas del III Congreso de Castellología Ibérica, Guadalajara, Diputación Provincial, pp. 657-680.

Molero, J. M. y Gallego, D. (2020), "La arquitectura militar de las órdenes militares en la Edad Media: evolución funcional, tipológica y constructiva", en J. M. Molero, D. Gallego e I. J. Gil (eds.), La construcción fortificada medieval: historia, conservación y gestión, Madrid, Instituto Juan de Herrera, 2020, pp. 89-110.

Monsalvo, J. M. (2017), "El conflicto nobleza frente a monarquía en el contexto de las transformaciones del estado en la Castilla Trastámara. Reflexiones críticas", en J. A. Jara (coord.), Discurso político y relaciones de poder. Ciudad, nobleza y monarquía en la Baja Edad Media, Madrid, Dykinson, pp. 89-207.

Orozco, P. y Parra, J. (ed.) (1978), [Primera] Historia de la Orden de Santiago. Introducción, trascripción, notas y apéndices del Marqués de Siete Iglesias, Badajoz, Diputación Provincial.

Palacios, J. S. (2006), "Castillos contra castillos: padrastros y fortalezas de asedio en la España medieval", Arqueología y territorio medieval, 13 (2), pp. 33-55.

- (2018), "Los ejércitos de las Órdenes Militares hispanas: otra aproximación al valor numérico de sus contingentes", en C. Ayala y S. Palacios (coord.), Hombres de religión y guerra. Cruzada y guerra santa en la Edad Media peninsular (ss. X-XV)", Madrid, Sílex, pp. 209-242.

Palencia, A. (ed.) (1904), Crónica de Enrique IV, ed. D. A. Paz, Madrid, Revista de Archivos.

Porras, P. A. (1997), La Orden de Santiago en el siglo XV. La provincia de Castilla, Madrid, Dykinson.

Pretel, A. (1978), Una ciudad castellana en los siglos XIV y XV (Alcaraz 1300-1475), Albacete, Instituto de Estudios Albacetenses.

- (2011), El Señorío de Villena en el siglo XV, Albacete, Instituto de Estudios Albacetenses.

Rades, F. (1572), Crónica de las tres Órdenes y Cavallerias de Santiago, Calatrava y Alcántara. Toledo, ed. facs., 1980.

Rivera, M. (1985), La Encomienda, el Priorato y la villa de Uclés en la Edad Media. Formación de un señorío de la Orden de Santiago (1174-1310), Madrid-Barcelona, CSIC.

Rodríguez, C. J. (2017), "La actividad político-militar y la ambición territorial de los marqueses de Villena en Extremadura a través del Memorial de Pedro de Baeza", eHumanista, 37, pp. 427-439.

- (2019), "Nuevas aportaciones sobre la campaña de Juan II contra los Infantes de Aragón en Alburquerque (1429-32)", E-Estratégica, 3, pp. 247-267.

Rodríguez, E. (2012), "La guerra en la baja Edad Media: un análisis a partir del asedio y defensa de la ciudad de Jaén en 1465", Trastámara, revista de Ciencias Auxiliares de la Historia, 9, pp. 113-126.

Rodríguez, M. (1996), "Poder y parentesco en la nobleza santiaguista del siglo XV", Noticiario de historia agraria: Boletín informativo del seminario de historia agraria, 12, pp. 55-90.

Rodríguez-Picavea, E. (2008), Los monjes guerreros en los reinos hispánicos. Las órdenes militares en la Península Ibérica durante la Edad Media, Madrid, La Esfera de los Libros.

Rubio, C. J. (2017), El Campo de Montiel en la Edad Media, Ciudad Real, Diputación Provincial.

Ruiz, F. (2000), "La hueste de las Órdenes Militares", en R. Izquierdo y F. Ruiz, Las órdenes militares en la Península Ibérica, Cuenca, Universidad de Castilla-La Mancha, vol. 1, pp. 403-436.

Sánchez, A. B. (2001), La casa de Mendoza. Hasta el tercer duque del infantado (1350- 
1531). El ejercicio y alcance del poder señorial en la Castilla Bajomedieval, Madrid, Palafox y Pezuela.

Salazar y Castro, L. (1697), Historia genealógica de la Casa de Lara, Madrid, Imprenta Llanos de Guzmán.

Schnell, P. y Baltuille, J. M. (2017), "Arqueología de la fortificación de la Guerra Civil y asociacionismo en los frentes de Madrid", Trabajos de arqueología Navarra, 29, pp. 169-200.

Suñe, J. (2013), "Técnicas de ataque y defensa en los asedios del siglo XIII: ámbito catalanoaragonés y occitano", GLADIUS, 33, pp. 113-130.

Val, M. I. (1991), "La sucesión de Enrique IV", Espacio, Tiempo y Forma, Serie III, $H^{a}$ Medieval, 4, pp. 43-78.

V.V.A.A. (1995), Alarcos, El Fiel en la balanza, Toledo, Junta de Comunidades de CastillaLa Mancha. 